\title{
The Relationship between Wave Trains in the Southern Hemisphere Storm Track and Rainfall Extremes over Tasmania
}

\author{
Carly R. Tozer, James S. Risbey, Terence J. O'Kane, Didier P. Monselesan, \\ AND MiCHAEL J. POOK \\ CSIRO Oceans and Atmosphere, Hobart, Tasmania, Australia
}

(Manuscript received 16 April 2018, in final form 2 October 2018)

\begin{abstract}
We assess the large-scale atmospheric dynamics influencing rainfall extremes in Tasmania, located within the Southern Hemisphere storm track. We characterize wet and dry multiday rainfall extremes in western and eastern Tasmania, two distinct climate regimes, and construct atmospheric flow composites around these extreme events. We consider the onset and decay of the events and find a link between Rossby wave trains propagating in the polar jet waveguide and wet and dry extremes across Tasmania. Of note is that the wave trains exhibit varying behavior during the different extremes. In the onset phase of rainfall extremes in western Tasmania, there is a coherent wave train in the Indian Ocean, which becomes circumglobal in extent and quasi-stationary as the event establishes and persists. Wet and dry extremes in this region are influenced by opposite phases of this circumglobal wave train pattern. In eastern Tasmania, wet extremes relate to a propagating wave train, which is first established in the Indian Ocean sector and propagates eastward to the Pacific Ocean sector as the event progresses. During dry extremes in eastern Tasmania, the wave train is first established in the Pacific Ocean, as opposed to Indian Ocean, and persists in this sector for the entire event, with a structure indicative of the Pacific-South American pattern. The findings regarding different wave train forms and their relationship to rainfall extremes have implications for extreme event attribution in other regions around the globe.
\end{abstract}

\section{Introduction}

Extreme multiday rainfall events have a large impact on society, from high rainfall leading to flooding to persistent low rainfall resulting in drought. Additionally, they can play an important role in water supply security, bringing reservoir-filling rains during the year (Pepler and Rakich 2010). It follows that there is keen interest in understanding the atmospheric processes associated with these extremes from the synoptic scale, including fronts, cutoff lows, and blocking highs (e.g., Catto and Pfahl 2013; Pfahl 2014), to the larger-scale atmospheric structures, like Rossby waves, which provide dynamic support to the synoptic processes (Pezza et al. 2012) and which may act as longer-range precursors of these extreme events (Wirth et al. 2018).

Our interest lies in rainfall extremes in the Southern Hemisphere midlatitudes and, in particular, in Tasmania, Australia (Figs. 1, 2). Our motivation for focusing on Tasmania relates to its location in the storm track and

Corresponding author: Carly R. Tozer, carly.tozer@csiro.au because it is the largest producer of renewable energy, primarily from hydropower, in Australia. Hydropower generation is a rainfall-sensitive industry, and thus an understanding of the processes influencing rainfall extremes in the region may assist in water resources and hydropower planning. We are interested in multiday rainfall extremes, as these have more potential for affecting runoff. That is, runoff may not be immediately generated following a single day of rainfall but may require an accumulation of rainfall days to increase soil moisture and subsequently produce runoff, which in turn may influence water supply operations. The hydropower catchments are located primarily in western Tasmania. There is an incomplete understanding of the atmospheric influences, particularly on a large scale, on multiday extremes in this region, beyond that it receives frontal rain due to its location in the midlatitude storm track (Godfred-Spenning and Gibson 1995; Pook et al. 2010; Lewis et al. 2018). Additionally, the region is on the windward side of topography running through the center of the state (Fig. 1b) and therefore receives much increased rainfall relative to eastern Tasmania (Fig. 1a). 

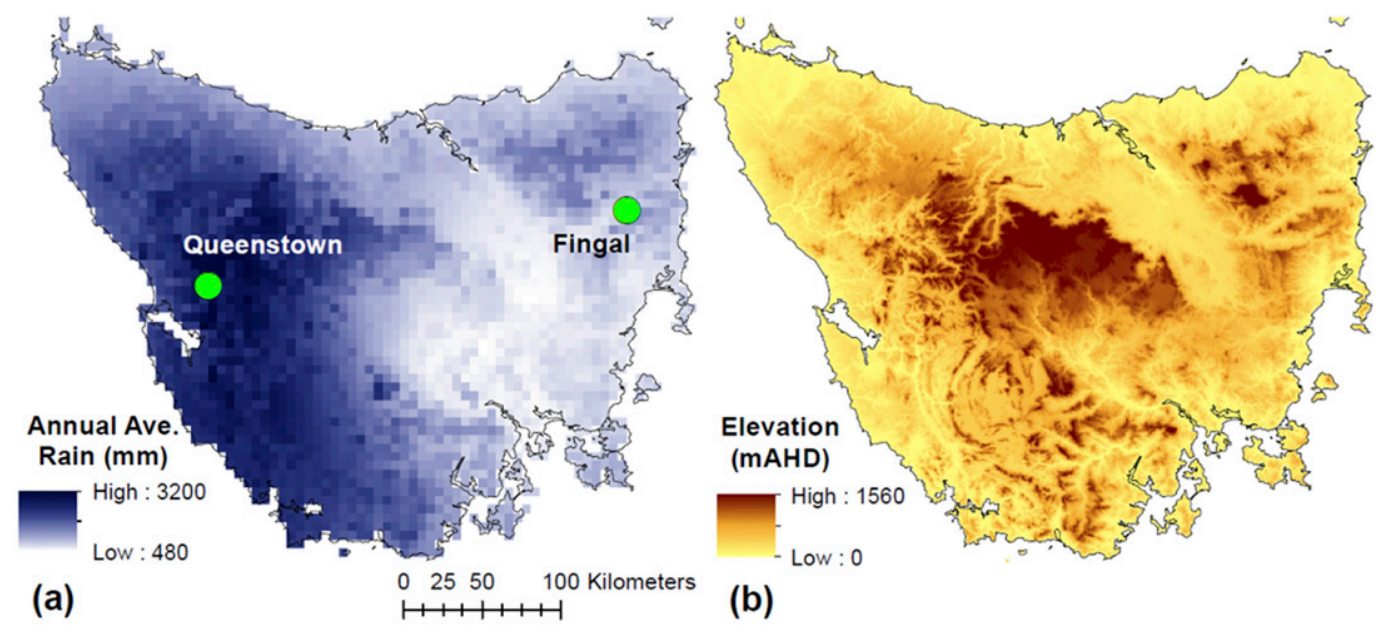

(b)
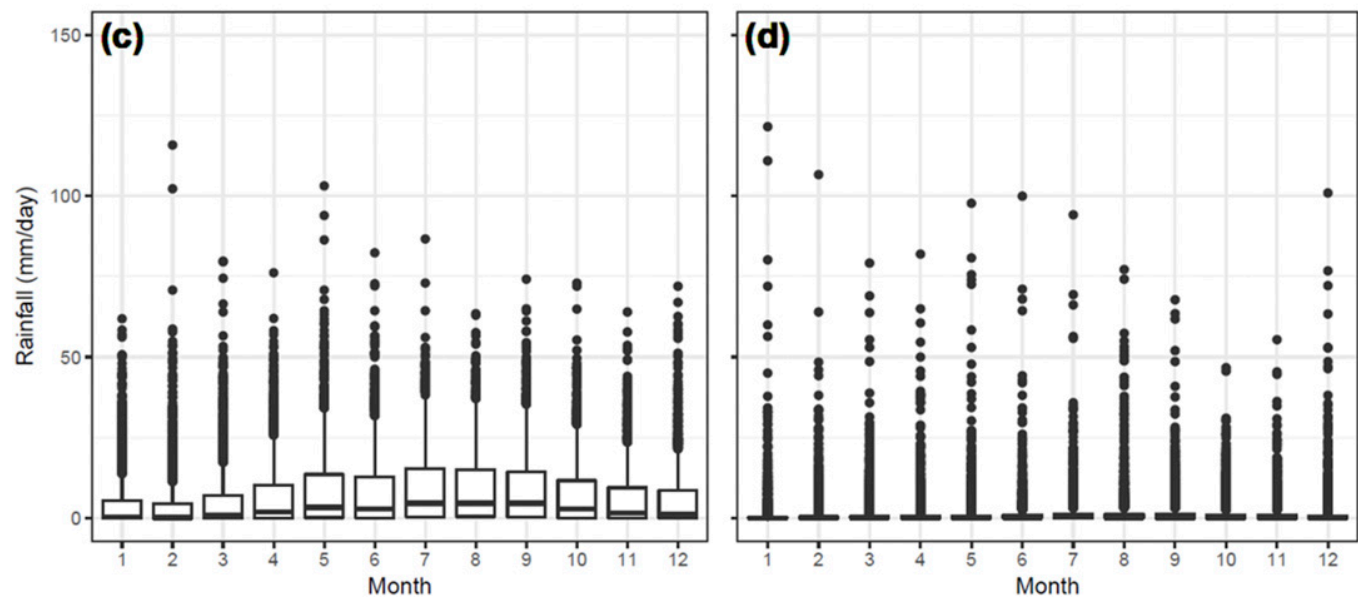

FIG. 1. Study region and relevant features. (a) Annual average rainfall across Tasmania calculated using the AWAP gridded rainfall product (Jones et al. 2009), with location of Queenstown and Fingal gauges indicated. (b) Topography across Tasmania (Global Map Australia 1M 2001, Geosciences Australia). Daily rainfall distribution in each month for the 1958-2016 period recorded at (c) Queenstown and (d) Fingal. See section 2 for discussion of gauged rainfall data sources.

Boxplots of the daily rainfall distribution in each month for rainfall recorded at representative gauges in western (Queenstown) and eastern (Fingal) Tasmania are presented in Figs. 1c and 1d and further highlight the difference in rainfall amounts received in both regions. Fingal records a far greater number of zero-rainfall days at $\approx 61 \%$, compared with $\approx 32 \%$ in Queenstown, though it can still experience very high daily rainfall amounts, as indicated by the extreme values in Fig. 1d. In general, eastern Tasmania has a climate regime more similar to southeast Australia (e.g., Pook et al. 2010; Risbey et al. 2009, 2013a,b), whereas western Tasmania experiences a far wetter climate.

We found no examples relating multiday rainfall extremes in the Tasmanian region to large-scale atmospheric processes. Temperature-related extremes in Australia, however, have been attributed to Rossby waves, which are "trains" of alternating high and low pressure systems that stretch zonally across the hemisphere. They have been referred to interchangeably as "Rossby wave trains" (Lau et al. 1994) and "Rossby wave packets" (Lee and Held 1993; Wirth et al. 2018) and typically span $1 / 3$ of the globe (Feldstein and Dayan 2008). In some cases, these trains extend around the globe and have been termed "circumglobal waveguide (or teleconnection) patterns" (Branstator 2002; Ding and Wang 2005). The term "waveguide" is used in reference to the subtropical and polar jets, which provide the channel within which these wave train patterns can exist and propagate (i.e., the jets act to "guide" the wave trains; Hoskins and Ambrizzi 1993). For example, Pezza et al. (2012) and Risbey et al. (2018) associated heat waves across Australia to blocking in the Australian region, preceded by a coherent Rossby wave train in the Indian Ocean, which persists into the Pacific Ocean as the event decays. Additionally, 


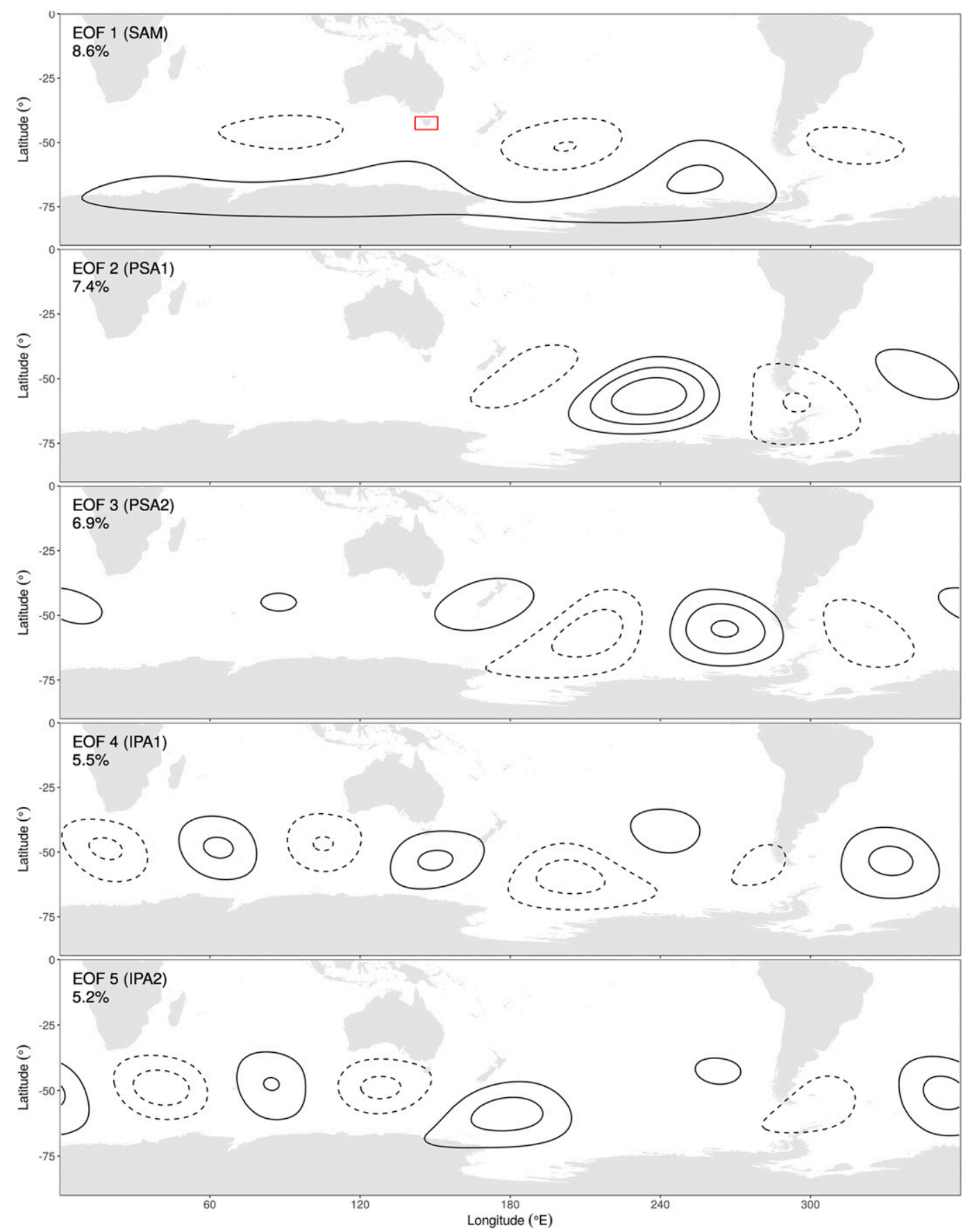

FIG. 2. EOFs of daily 500-hPa geopotential height anomalies using the Japanese 55-year Reanalysis. These are derived by including all days in the 1958-2016 period in the analysis. Solid (dashed) contours indicate positive (negative) anomalies. The variability accounted for by each pattern is provided. See section 2 for a discussion of the reanalysis dataset. The red square identifies the location of Tasmania in the context of Australia and the Southern Hemisphere.

Reeder et al. (2015) found that extreme summertime cold fronts, which are associated with wildfires in southeastern Australia, are preceded by a propagating wave train in the polar jet waveguide. In South America,
Müller and Ambrizzi (2007) found winter frosts in southern South America to be associated with a blocking high over the region, which forms part of concurrent wave trains propagating in the subtropical and polar jet 
waveguides. Some Northern Hemisphere-based studies have similarly found rainfall extremes to be associated with these large-scale wave trains. Teng and Branstator (2017), for example, found that winter droughts in California are related to extreme ridging near the west coast of North America, which is in turn associated with a wave train in the mean Northern Hemisphere jet. In the Alps, Grazzini (2007) attributed extreme rainfall and flooding to the presence of a high-amplitude upper-level trough over the region and a downstream ridge, which are a part of a broader, propagating wave train in the jet stream waveguide. Feldstein and Dayan (2008) also found that both wet and dry winter episodes in Israel are associated with eastward-propagating wave trains of near-global extent.

In addition to their relationship with extreme events, some wave train patterns are noted as being recurrent features of the flow in the troposphere (e.g., Lau et al. 1994; Mo and Higgins 1998; O'Kane et al. 2016), meaning that when these patterns are expressed, they appear in preferred geographic locations. In the Southern Hemisphere, the Pacific-South American 1 (PSA1) and 2 (PSA2) patterns are such structures. These patterns feature alternating high and low pressure systems across the Pacific Ocean and into the South Atlantic Ocean (Lau et al. 1994) and are typically identified as the second and third empirical orthogonal functions (EOFs) of the midtropospheric flow, with the wellknown southern annular mode (SAM) identified as EOF1 (Rogers and van Loon 1982; Thompson and Wallace 2000).

For reference, we present the first five EOFs of daily 500-hPa geopotential height anomalies in Fig. 2. The EOFs are the invariant patterns that maximize the variance in the geopotential height field. In the patterns presented in Fig. 2, the anomalies can vary in sign and amplitude via the multiplication of the EOF pattern with its corresponding principal component time series. PSA1 and PSA2 explain similar amounts of variability $(7.4 \%$ and $6.9 \%$, respectively) and have similar structures, though the center of the PSA1 pattern (i.e., region of highest amplitude) is located in the central Pacific, while for PSA2 this center is shifted approximately $30^{\circ} \mathrm{E}$ toward South America. The PSA pattern in general varies on a range of time scales, with the greatest percentage of variance occurring on the synoptic to intraseasonal time scales (O'Kane et al. 2017). Hill et al. (2009) found a relationship between interannual rainfall in Tasmania and both the PSA and SAM. The next pair of patterns, EOFs 4 and 5 , account for $5.5 \%$ and $5.2 \%$ of the variance in the geopotential height field, respectively. They similarly look like wave trains but have an increased expression in the Indian Ocean relative to PSA1 and PSA2, as also shown in Fig. 2 of O'Kane et al. (2017). We label these patterns Indian-Pacific-Atlantic 1 (IPA1) and 2 (IPA2). In regards to the persistence characteristics of the IPA patterns, O'Kane et al. (2017) found that modes of variability in the Indian Ocean tend to be more transient relative to those in the Pacific, with the majority of the variance on the synoptic time scales. We note that EOFs do not necessarily represent physical patterns and that EOF analysis is based on singular value decomposition and makes various assumptions, of which stationarity in the time series is the most restrictive (O'Kane et al. 2016). However, several authors have identified these largescale patterns in different atmospheric fields (Lau et al. 1994; Branstator 2002; Mo and Higgins 1998), and others, using less restrictive clustering methods (e.g., Risbey et al. 2015; O'Kane et al. 2013, 2016; Irving and Simmonds 2016), have identified similar persistent tropospheric structures to those revealed in Fig. 2, which suggests that these patterns are robust atmospheric features.

The attribution of extreme events to coherent largescale wave train patterns is important because these patterns have persistence (Mo and Higgins 1998; O'Kane et al. 2017) and show some predictability (e.g., Grazzini 2007; Grazzini and Vitart 2015), as opposed to extremes being a result of less predictable stochastic mechanisms (Lucarini et al. 2016). We thus aim to identify wet and dry multiday extreme rainfall events across Tasmania and to diagnose any associated largescale atmospheric dynamics around these events. We are interested in identifying, through composite analysis, whether the atmospheric patterns associated with the extremes have any coherency, particularly in relation to the recurrent large-scale wave train patterns discussed above.

\section{Data and methods}

The two key steps involved in this analysis are 1) the identification of wet and dry extreme events in western and eastern Tasmania at the Queenstown and Fingal gauges and 2) the development of atmospheric flow composites around these events. The Fingal rainfall gauge (gauge 092012; Fig. 1) is classed as an Australian Bureau of Meteorology high-quality gauge (Lavery et al. 1997). The Queenstown gauge (gauge 097008) includes observed data where available and is supplemented by interpolated estimates when observations are missing (Jeffrey et al. 2001). Daily data are available for both gauges since the late 1800s; however, only data from 1958 to 2016 are used to match the availability of reanalysis data. We use the Japanese 55-year Reanalysis (Kobayashi et al. 2015), which provides a modern four-dimensional variational analysis from 1958 to present at a resolution of $0.5^{\circ}(\sim 55 \mathrm{~km})$, 
though we use a $1.25^{\circ}$-resolution version of this product here. Details are presented in Kobayashi et al. (2015). Note that O'Kane et al. (2016) assessed Southern Hemisphere waveguide modes using geopotential height fields from the Japanese 55-year Reanalysis and the ECMWF interim reanalysis (ERA-Interim), which has a model resolution of $0.75^{\circ}(\sim 80 \mathrm{~km})$, and found similar results.

Rainfall series are inherently "noisy," and it is difficult to demarcate clear events. In our approach to defining wet extreme events, we sought to identify periods where rainfall occurred continuously over a sequence of days, so that the event was more likely to contribute to runoff events, and where the cumulative rainfall from the sequence was among the highest recorded for such sequences. The choice of how to bound such events is somewhat arbitrary, since a choice to have zero rainfall as an event bound could result in very long sequences in some locations, where many of the rainfall days are not associated with much rainfall. Our interest is in capturing processes broadly on synoptic and large scales (220 days) where coherent dynamical processes are able to contribute to the event. With this in mind, we chose to set an event bound of the 25 th percentile value of rainfall of rain days, where the 25 th percentile was calculated separately for each season. This ensures that our sequences contain substantive rainfall on each day of the event. An initial "events" list was thus formed by selecting any number of days in a row above the 25 th percentile value (e.g., events could be 1 or 10 days long). The cumulative total rainfall recorded during each of these events was then calculated, and from these values, the 95th percentile event rainfall amount was determined. Any event with a rainfall amount less than the 95 th percentile value was then removed from the list, which meant that singleday events were typically discarded. The remaining events with totals above the 95th percentile formed the final list of wet extreme events. This process was undertaken for each season and location separately. It should be noted that in addition to the above wet extremes definition, we also tested definitions where we selected individual days that recorded a rainfall total greater than the 99th percentile (wet spikes) and also wet spells, which were identified as at least 3 days in a row of rainfall larger than the 85 th percentile, where the 85 th percentile was calculated across a shifting 11-day window. We performed the composite analysis described below on these definitions. Though the wet extremes events identified via each method have slightly different persistence characteristics (e.g., our chosen wet events definition recorded longer events than those identified through the wet spikes and wet spells definitions), we found similar composite atmospheric patterns for all definitions for both Queenstown and Fingal (not shown). This suggests that our results are robust to wet event definition and that there is indeed a common and coherent atmospheric pattern associated with extreme wet events for Queenstown and Fingal.

Extreme dry events were identified using a different method, given that the "dry" end of the rainfall distribution is bounded by zero. Dry events were thus identified as consecutive zero-rainfall days. The number of consecutive days required to be classified as a dry event was different for Queenstown and Fingal, given the markedly different number of zero-rainfall days recorded at both sites (section 1). For Queenstown, we identified extreme dry events as 6 zero-rainfall days in a row, and for Fingal, this threshold was 10 days. The above wet and dry extreme event definitions allowed for a reasonable number of events to be classified for both locations and across all seasons, without having to modify the definitions for each season, which allows direct comparison of the seasonal results. The sample size used in compositing analyses is typically a subjective choice, but we felt a "reasonable" number was one that is not too large so as to represent mean conditions and not too small so that the resulting event composites have low signal to noise. We had a broad aim of around one event per season per year of analysis in satisfying these criteria.

The total number of wet and dry extreme events identified at each location across the 1958-2016 period is given in Table 1. The start day of each wet/dry event was designated as "day 0," and the 10 days before and after day 0 were then designated as days -10 to 10 . The composite (average) atmospheric flow was determined for each of these days in order to identify the onset, start, and decay periods of the extreme wet and dry rainfall events. By compositing the atmospheric flow, it is hoped that a common dynamical pattern can be identified where there is consistency across events.

In the results that follow, we present composites for a subset of the event days (days $-5,-3,-2,-1,0,1,2,5$, and 7) featuring five key atmospheric flow diagnostics: geopotential height anomalies at $500 \mathrm{hPa}$, zonal wind at $300 \mathrm{hPa}$, wave activity flux (Takaya and Nakamura 1997, 2001) at $500 \mathrm{hPa}$, Eady growth rate (Hoskins and Valdes $1990)$ at $500 \mathrm{hPa}$, and stationary Rossby wavenumber (Hoskins and Ambrizzi 1993) at $200 \mathrm{hPa}$.

Negative geopotential height anomalies are indicative of low pressure systems (troughs, cutoff lows), and positive anomalies indicate high pressure systems (ridges, anticyclones) in the midtroposphere. Where anticyclones persist over a number of days and block the flow, they are typically referred to as "blocking highs" or simply "blocks" (e.g., Trenberth and Mo 1985). The geopotential height anomalies are calculated relative to the 1958-2016 mean field and have units of meters. Zonal wind is used as an 
TABLE 1 . Wet and dry extreme events in Queenstown and Fingal.

\begin{tabular}{lcccccc}
\hline \hline & Total & Autumn & $\begin{array}{c}\text { Median autumn } \\
\text { event length }\end{array}$ & $\begin{array}{c}\text { Max autumn } \\
\text { event length }\end{array}$ & $\begin{array}{c}\text { Median total autumn } \\
\text { event rainfall (mm) }\end{array}$ & $\begin{array}{c}\text { Median daily autumn } \\
\text { event rainfall (mm) }\end{array}$ \\
\hline Queenstown wet & 174 & 43 & 12 & 23 & 200 & 19 \\
Queenstown dry & 183 & 49 & 6 & 14 & - & - \\
Fingal wet & 160 & 38 & 4 & 11 & - & 16 \\
Fingal dry & 231 & 68 & 13 & 42 & - \\
\hline
\end{tabular}

indicator of the position of the subtropical and polar jet waveguides and has units of meters per second. Wave activity flux is a measure of wave activity in the horizontal plane and is presented as vectors, which show propagation of stationary eddies in wave packets within the waveguides. The eddies are stationary in the sense that their phase speed is assumed to be zero, but the wave packet propagates in the direction of the flow relative to the earth at a group velocity that is greater than the velocity of the background flow. Wave activity flux $\left(\mathrm{m}^{2} \mathrm{~s}^{-2}\right)$ is calculated based on the daily low-pass-filtered (30-day cutoff) horizontal wind components $U$ and $V$ and perturbation streamfunction $\psi^{\prime}$ following Takaya and Nakamura (1997, 2001):

Wave activity flux

$$
=\frac{p}{2|\mathbf{U}|}\left[\begin{array}{l}
U\left(\psi_{x}^{\prime 2}-\psi^{\prime} \psi_{x x}^{\prime}\right)+V\left(\psi_{x}^{\prime} \psi_{y}^{\prime}-\psi^{\prime} \psi_{x y}^{\prime}\right) \\
U\left(\psi_{x}^{\prime} \psi_{y}^{\prime}-\psi^{\prime} \psi_{x y}^{\prime}\right)+V\left(\psi_{y}^{\prime 2}-\psi^{\prime} \psi_{y y}^{\prime}\right)
\end{array}\right] ;
$$

$p$ is $p^{\prime} / 1000 \mathrm{hPa}$, where the $p^{\prime}=500 \mathrm{hPa}$ is the pressure of the isobar on which wave activity flux is calculated in this analysis.

Eady growth rate $\left(\right.$ day $\left.^{-1}\right)$ measures baroclinic instability (i.e., instability in the vertical plane) (Hoskins and Valdes 1990) and is calculated as

$$
\text { Eady growth rate }=0.31 \frac{f}{N}\left|\frac{\partial \mathbf{v}}{\partial \mathbf{z}}\right|
$$

where $f$ is the Coriolis parameter, $N$ is the Brunt-Väisälä frequency (Lee and Mak 1994), $z$ is the vertical distance, and $\mathbf{v}$ is the horizontal wind vector at 450 and $550 \mathrm{hPa}$.

Rossby wavenumber helps to identify the regions in which Rossby waves propagate, whereby stationary Rossby waves are refracted toward larger wavenumbers and do not propagate where the Rossby wavenumber is less than zero (Hoskins and Ambrizzi 1993). Rossby wavenumber is calculated as

$$
\text { Rossby wavenumber }=a \cos \phi\left(\frac{\beta}{\bar{U}}\right)^{1 / 2},
$$

where $\bar{U}$ is the idealized climatological mean zonal flow, $\beta$ is the daily meridional absolute vorticity gradient, $a$ is the radius of Earth, and $\phi$ is latitude. We assess Rossby wavenumber at $200 \mathrm{hPa}$ and focus on the regions where Rossby waves do not propagate (Rossby wavenumber $<0$ ), which we refer to as "no-go" zones.

In addition to the above diagnostics, we assess Rossby wave source at $300 \mathrm{hPa}$ (Sardeshmukh and Hoskins 1988), velocity potential anomalies at $300 \mathrm{hPa}$, divergent winds at $300 \mathrm{hPa}$, and rainfall deciles. Velocity potential indicates the divergent component of the horizontal velocity field, given by $\nabla \cdot \mathbf{v}=\nabla^{2} \chi$ (Lynch 1988), with units of $\mathrm{m}^{2} \mathrm{~s}^{-1}$. Negative velocity potential anomalies indicate areas of diverging winds and rising air. In the extratropics, this implies deep convection and therefore enhanced rainfall (O'Kane et al. 2016). The opposite is the case for positive anomalies. We also present the divergent winds, which are indicated by the vector components of $\mathbf{v}_{\chi}=\nabla \chi$ and have units of $\mathrm{m} \mathrm{s}^{-1}$. Rossby wave source is calculated as $-\nabla \cdot\left(\zeta v_{\chi}\right)$, where $\zeta$ is absolute vorticity, and $v_{\chi}$ is the divergent component of horizontal velocity (Sardeshmukh and Hoskins 1988) and has units of $10^{-11} \mathrm{~s}^{-2}$. At $300 \mathrm{hPa}$, positive Rossby wave source values are associated with divergence (Shimizu and de Albuquerque Cavalcanti 2011; O'Kane et al. 2016) and therefore rainfall. We also present rainfall deciles, which represent the decile in which the composite event rainfall sits relative to all rain days (i.e., days with $>0.0 \mathrm{~mm}$ of rain) in the respective season. A rainfall decile of 1 indicates very low rainfall, and a decile of 10 indicates very high rainfall. We only present rainfall deciles $\geq 7$ to show regions of high rainfall.

\section{Life cycle of extreme rainfall events}

We assessed the life cycle of extreme events in Queenstown and Fingal for all four seasons based on the 1958-2016 period. We undertook a seasonal analysis due to the seasonal variability in rainfall (Fig. 1) and atmospheric dynamics (e.g., the mean subtropical jet is generally not present in summer and strongest in winter). Further, water resources management decisions are often made on a seasonal basis (e.g., Goddard et al. 2010). Upon review of the seasonal results, we found only subtle differences in the atmospheric patterns around wet and dry extremes identified for each season at each location. 


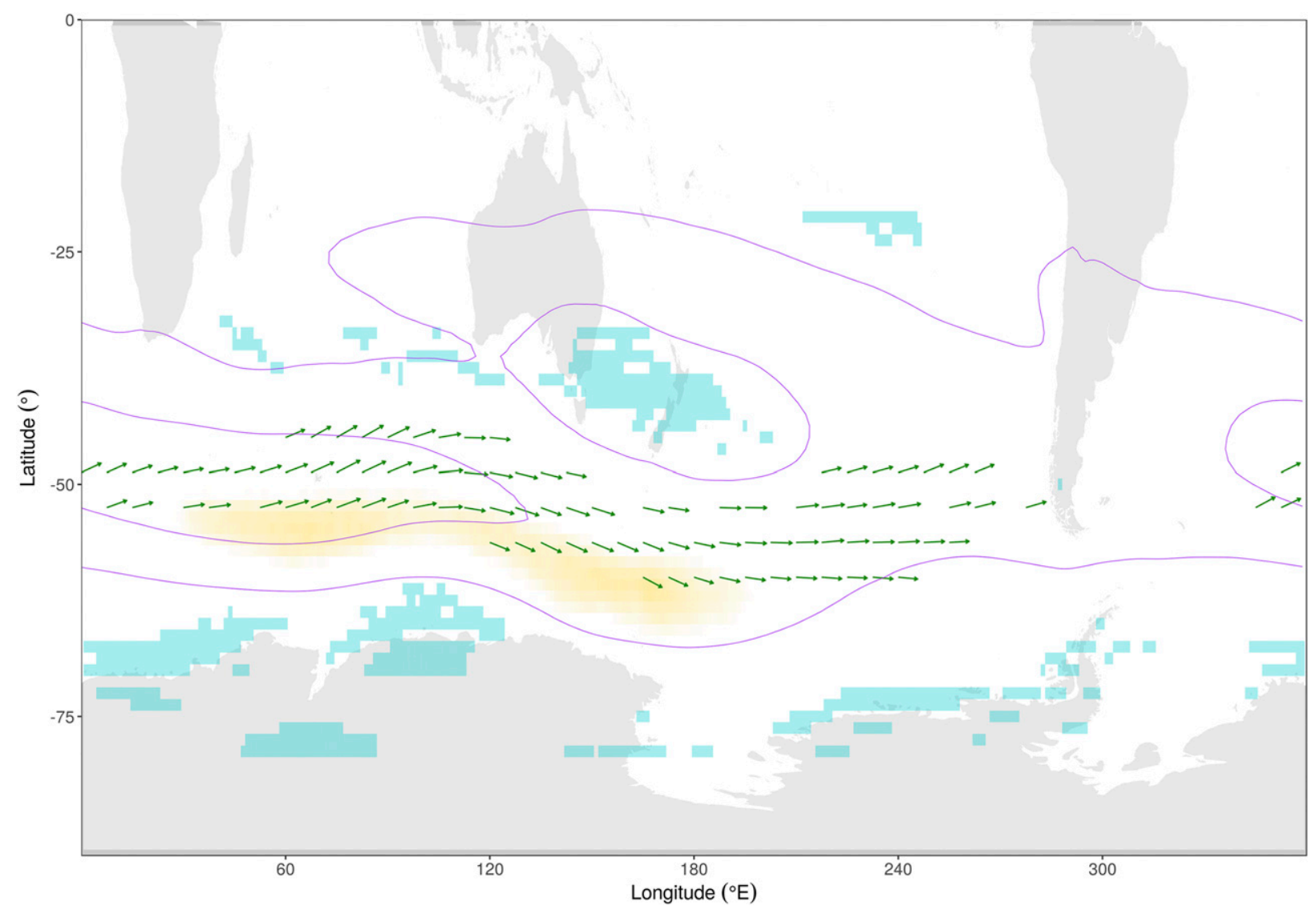

FIG. 3. Autumn mean Eady growth rate at $500 \mathrm{hPa}$ (yellow shading), Rossby wavenumber at $200 \mathrm{hPa}$ where only regions $<0$ are shown (cyan shading), wave activity flux at $500 \mathrm{hPa}$ (green vectors), and zonal wind at $300 \mathrm{hPa}$ (purple contours). Green vectors show wave activity flux with magnitudes greater than the 95 th percentile. Rossby wavenumber is only shown between latitudes of $-20^{\circ}$ and $-80^{\circ}$. Only Eady growth rate values $>1.1 \mathrm{day}^{-1}$ are shown.

The similarities across seasons may be due to the key dynamics associated with each of the wet and dry extremes cases lying within the polar jet, which shows low variability across the seasons [see Fig. 8 in O'Kane et al. (2016)]. Given this, we also performed the analysis on the full year, considering all seasons together. We found the full-year composite patterns to be similar to those identified for individual seasons, though again there were subtle differences, given that the full-year composites incorporate all seasonal variability in the rainfall and atmospheric dynamics into the one composite (see Fig. A3 in the appendix). Of importance is that the results of the full-year analysis further confirm that there is indeed a coherent atmospheric pattern associated with rainfall extremes in Queenstown and Fingal across the year. We choose, however, to present the seasonal analyses for the reasons listed above and, as an example, present results for the autumn season.

We present the mean Eady growth rate, wave activity flux, zonal wind, and Rossby wavenumber fields calculated for all autumn days over the 1958-2016 period in Fig. 3. The mean field presents a standard against which to assess how anomalous the atmospheric flow around the extreme events is. Figure 3 shows that, on average, maxima of both the baroclinic instability (yellow shading) and wave activity (green vectors) lie in the polar jet, which is identified by the zonal wind (purple contours). Also of note is the presence of a no-go zone (i.e., regions with Rossby wavenumber $<0$ ), which partially covers southeastern Australia and New Zealand and provides only a very coarse wave channel in the climate mean.

The total number of autumn wet and dry extreme events and median and maximum autumn event lengths are presented in Table 1. Additionally, we present the median total wet event rainfall at both Queenstown and Fingal, along with the median daily event rainfall. The latter was determined by calculating the mean daily rainfall recorded for each event (i.e., total event rainfall divided by number of event days) and then finding the median of all these values. The values in Table 1 indicate that although the wet 


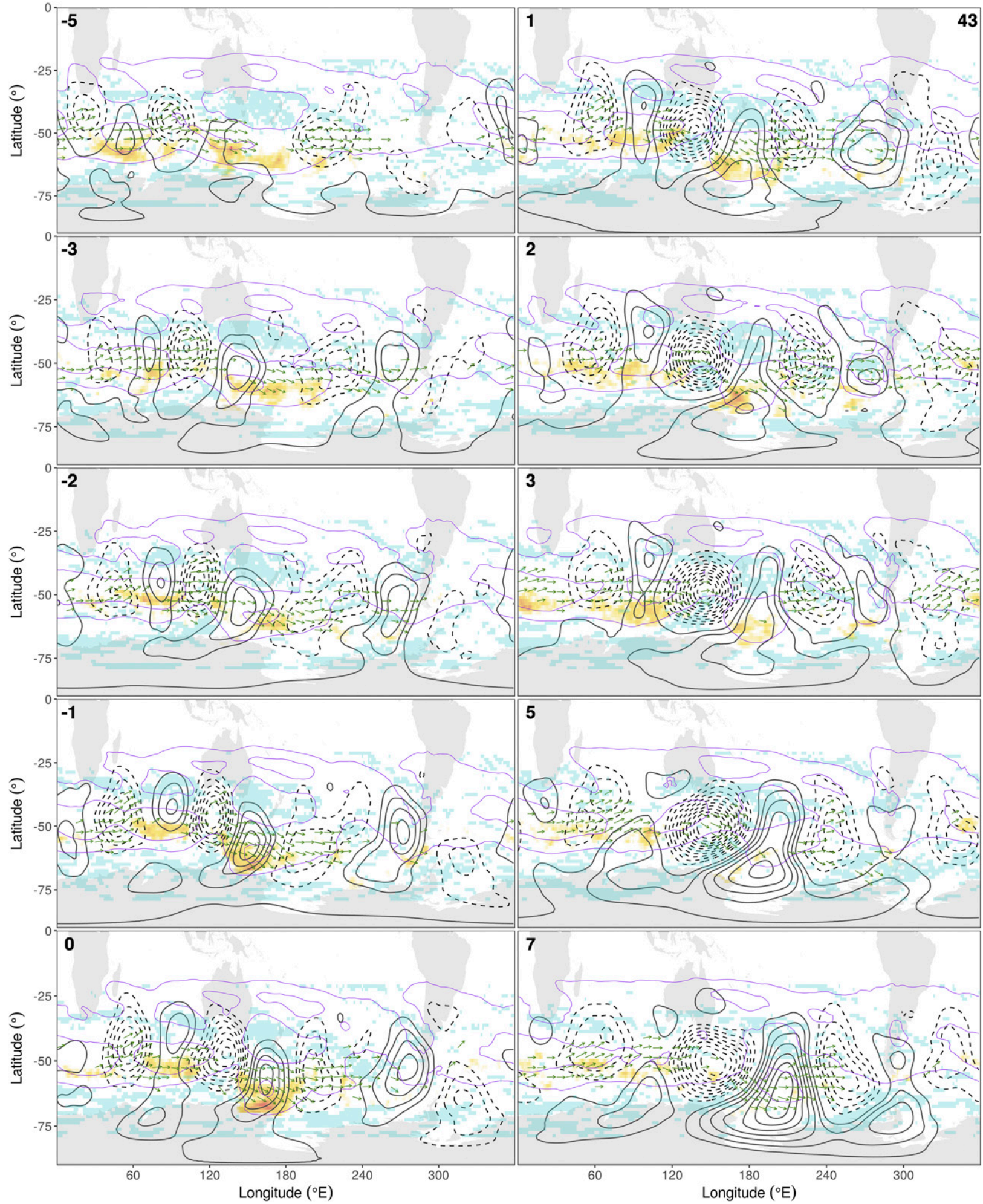

FIG. 4. Composite circulation for Queenstown wet events for days $-5,-3,-2,-1,0,1,2,3,5$, and 7 , showing Eady growth rate at $500 \mathrm{hPa}$ (yellow/red shading), Rossby wavenumber at $200 \mathrm{hPa}$ where only regions $<0$ are shown (cyan shading), wave activity flux at $500 \mathrm{hPa}$ (green vectors), geopotential height anomalies (black contours), and zonal wind (purple contours). Green vectors show wave activity flux with magnitudes greater than the 95th percentile. Solid (dashed) contours indicate positive (negative) geopotential height anomalies, filtered to only show values $>15$ or $<-15 \mathrm{~m}$, with contours every $15 \mathrm{~m}$. Zonal wind field is filtered to show winds $>20 \mathrm{~m} \mathrm{~s}^{-1}$, 
events in Queenstown persist for longer and therefore have a higher median total event rainfall, the median daily rainfall values received during wet extreme events at Queenstown and Fingal are similar. Additionally, Table 1 indicates the large difference in the median event length for Queenstown dry and Fingal wet events, compared with Queenstown wet and Fingal dry events. The difference results from both the very different climate regimes of each location (Fig. 1) and the way in which we have defined our events. For example, we deliberately set the threshold for Fingal dry events at 10 days because shorter thresholds resulted in far larger sample sizes (because of Fingal's drier climate), so that our "extreme" events would likely resemble mean conditions. We note that the difference between the event lengths means that we may be identifying longer-lived dynamical processes for Queenstown wet and Fingal dry events, which may differ from the types of processes identified for Queenstown dry and Fingal wet events, which have shorter median event lengths. We discuss the potential implications of this in the following subsections.

We assessed the significance and variability in the composite patterns and present the results in the appendix, though we provide discussion of them in section 3. In summary, to test the significance of the composite atmospheric patterns (as represented by the geopotential height anomalies), we compared them to the 5th and 95th percentile geopotential height anomalies that were generated by randomly sampling nonevent days. This analysis indicated that we are unlikely to obtain the coherent patterns we identify around the Queenstown and Fingal wet and dry events simply by chance. To assess the variability (or spread) in the composite samples, we calculated the signal-to-noise ratio (absolute mean divided by standard deviation) of geopotential height anomalies for each grid point for each event day. While this is not strictly a test of significance of the composite patterns, it gives an indication of the spread within each event-day sample. The results indicate that there is some noise in the patterns, particularly around the atmospheric structures remote from Tasmania. We discuss this issue in greater detail in section $3 \mathrm{a}$ and the appendix.

\section{a. Wet extremes in Queenstown}

Figure 4 presents the composite circulation for autumn extreme wet events in Queenstown. Wave activity, indicated by the green vectors, primarily sits in the polar jet waveguide channel, which is additionally demarcated by the zonal wind contours and the no-go zones. Throughout the event, the no-go zones are far more extensive than the autumn mean no-go zones presented in Fig. 3, spanning now much of the Indian, Australian, and Pacific regions. These zones act to concentrate the waveguide and push it farther poleward. An organized wave train is evident in the Indian Ocean by day -3 , as indicated by the alternating negative and positive geopotential height anomalies, and by day -1 , this pattern spans the hemisphere. The composite pattern features a high pressure system, which sits south of New Zealand and persists in this region for around 5 days. This blocking high slows the westerly flow and allows for the formation of a trough, which sets up over Tasmania by day 0 . This long-wave trough allows the repeated passage of short waves and westerlies over Tasmania throughout the event.

Eady growth rate (i.e., baroclinic instability) is confined to the polar waveguide, like in the autumn mean (Fig. 3). However, throughout the wet extremes events, it is of greater intensity relative to the climatological mean (i.e., orange/red shading as opposed to just yellow) and is highly localized on the poleward flank of the anticyclones immediately upstream and downstream of the trough over Tasmania. Past studies have associated baroclinic instabilities with the formation of Rossby wave packets (O'Kane et al. 2013, 2016; Wirth et al. 2018) and, in particular, with the onset of blocking (Frederiksen 1982, 1983; Nakamura and Wallace 1993; Nakamura et al. 1997). Our results also suggest that baroclinic instability plays some role during much of the life cycle of the wave train patterns presented here. The active parts of the individual pressure systems (suggested by the baroclinic instability and wave activity flux vectors) sit within the waveguide channel; however, they do extend outside of this channel. The wave activity flux vectors indicate barotropic instability and do not propagate in the no-go zone but feed into the part of the structures that sit within the polar waveguide. Of note is that the circumglobal extent of the composite wave train pattern persists from day 0 to day 7 (Fig. 4) and beyond (discussed in section 4). The persistence of this wave train pattern fits with the long-lived nature of wet extremes in Queenstown (as they have been defined in this analysis).

\footnotetext{
with contours every $10 \mathrm{~m} \mathrm{~s}^{-1}$. Rossby wavenumber is only shown between latitudes of $-20^{\circ}$ and $-80^{\circ}$. Only Eady growth rate values $>1.1$ day $^{-1}$ are shown. Note that the color scale applied to the Eady growth rate field is the same as that shown in Fig. 3 . The day number is given in the top-left corner of each panel, and the total number of wet autumn events is given in the top-right corner.
} 


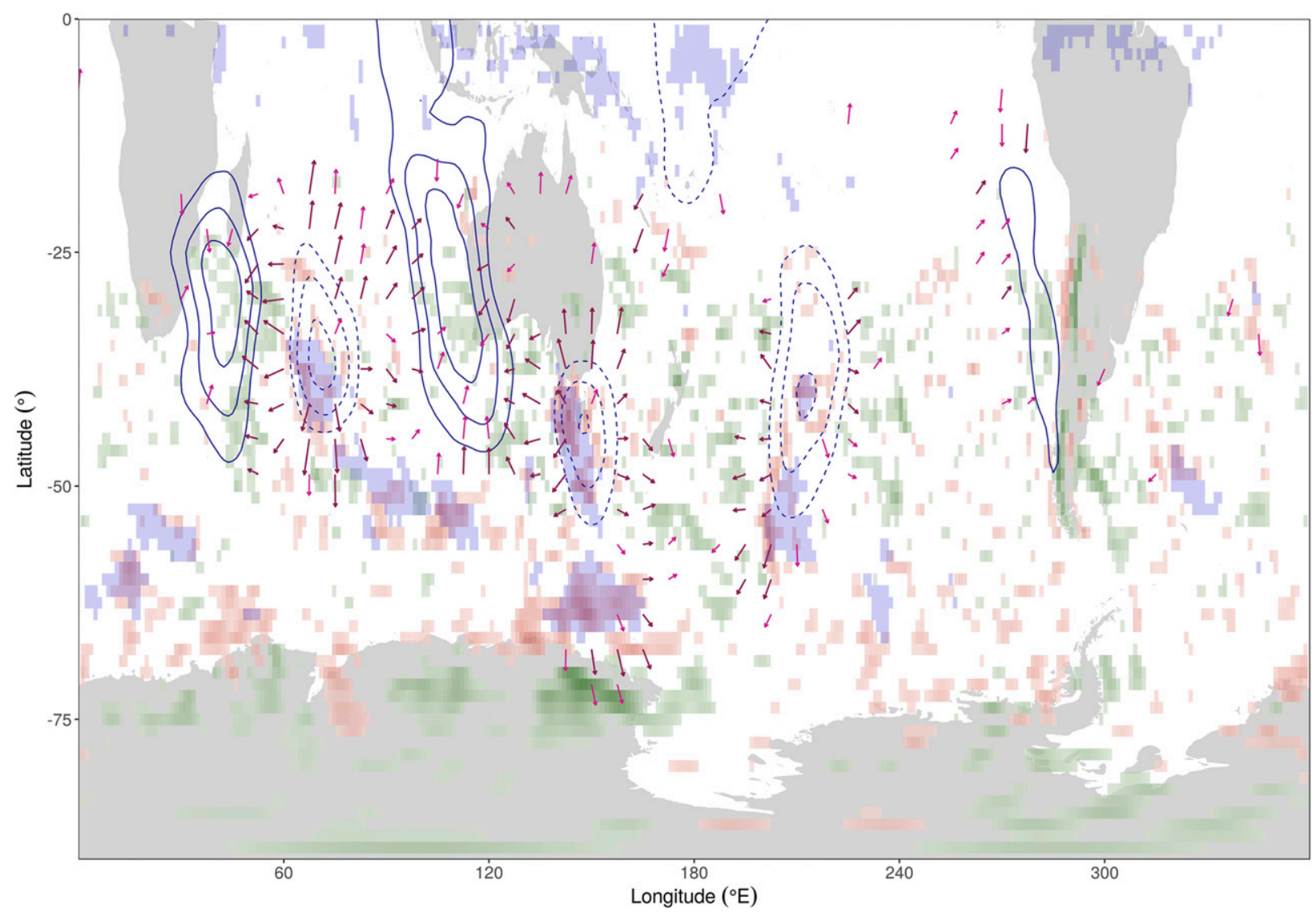

FIG. 5. Composite circulation for day 0 for Queenstown wet events, showing rainfall deciles $\geq 7$ (blue shading), Rossby wave source at $300 \mathrm{hPa}$ (green and red shading), velocity potential anomalies at $300 \mathrm{hPa}$ (dark blue contours), and divergent winds (pink vectors). Red (green) shading indicates positive (negative) Rossby wave source, filtered to show values $>20$ and $<-2010^{-11} \mathrm{~s}^{-2}$ only. Solid (dashed) contours indicate positive (negative) velocity potential anomalies, filtered to show values $>600000 \mathrm{or}<-600000 \mathrm{~m}^{2} \mathrm{~s}^{-1}$. Pink (dark pink) vectors show divergent winds with magnitudes greater than the 90th (95th) percentile.

The high rainfall in western Tasmania, resulting from the wave train pattern in Fig. 4, is shown in Fig. 5 (blue shading). As expected, the enhanced rainfall coincides with negative velocity potential anomalies, diverging upper-level winds (rising air), and positive Rossby wave source. The negative velocity potential anomalies are centered on the region of high negative-positive gradients in the geopotential height anomaly field, and vice versa for positive velocity potential anomalies. We summarize the three-dimensional atmospheric structure associated with wet extremes in western Tasmania in the schematic presented in Fig. 6, guided by the day 0 dynamics presented in Figs. 4 and 5. At the surface, a trough sits over Tasmania (indicated by mean sea level pressure contours), with winds converging on the region. In the midtroposphere (e.g., 500-hPa pressure level), this trough is expressed as part of a circumglobal wave train. The wave activity flux vectors in Fig. 6 indicate that the active part of the wave train sits within the polar jet. Air rises over Tasmania (indicated by the pink dashed arrows), with diverging winds aloft (around 300-hPa pressure level), as shown by the fuchsia vectors.

Although the composite results show that a coherent wave train pattern is associated with wet extreme events in western Tasmania, we acknowledge that there is some noise in the composite waveguide features that are remote to Tasmania (appendix). As an independent test of the association between large-scale wave train patterns and wet extremes in Tasmania, we assess whether the EOF patterns presented in Fig. 2 are expressed in the atmosphere during the extremes events. To do this, we calculate the mean index value for the associated principal components of each EOF for each event day. We compare the mean index values to the 5th and 95th percentile intervals calculated from a Monte Carlo process (described further in Fig. 7 caption). When the event-day mean index value is less than the 5 th or greater than the 95th percentile mean index values (i.e., the index value is high, whether highly negative or 


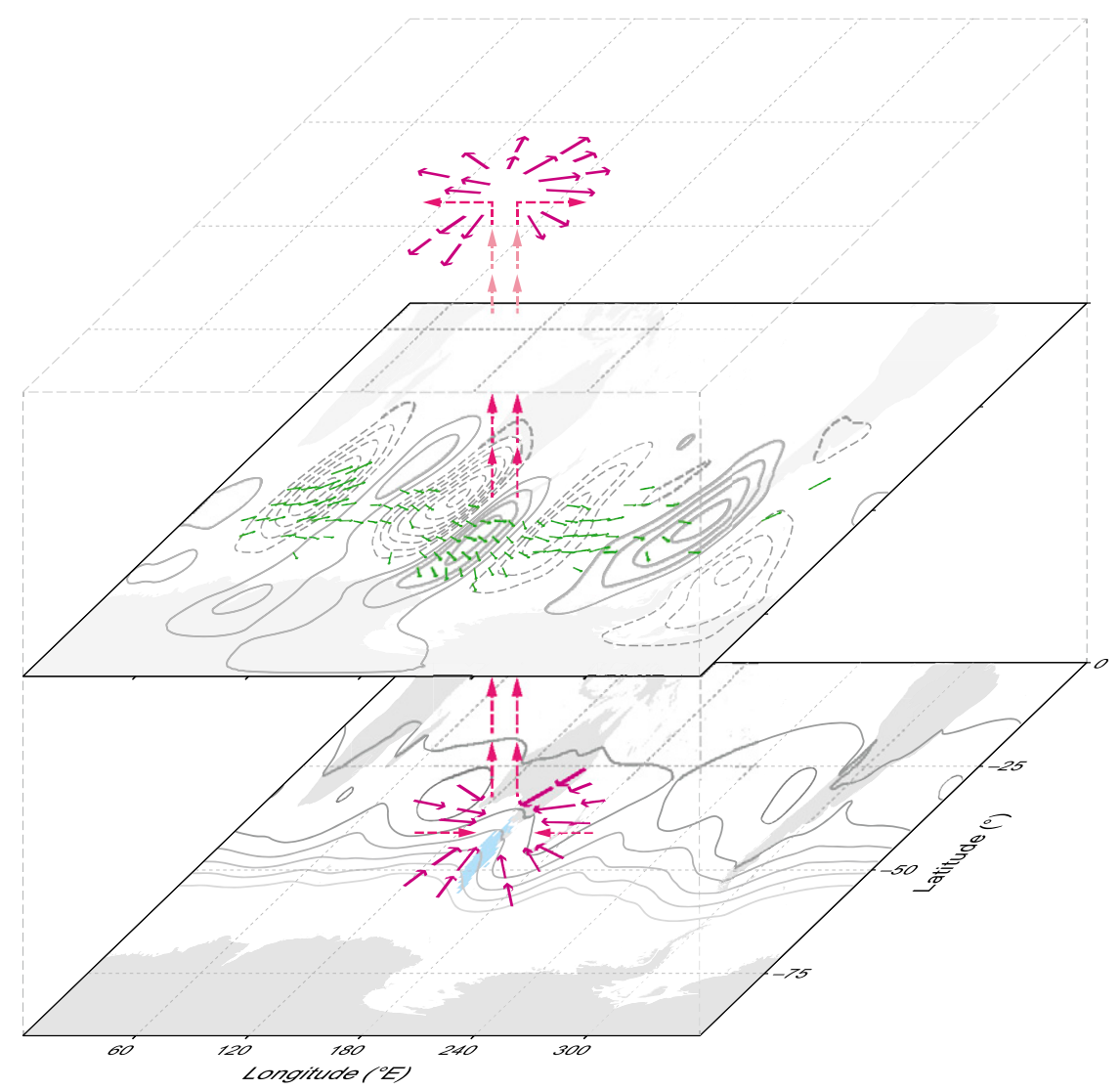

FIG. 6. Schematic of atmospheric flow associated with wet extremes in Queenstown. Mean sea level pressure (gray contours) and rainfall deciles $\geq 7$ (blue shading) are presented on the surface layer. In the midtroposphere (e.g., $500 \mathrm{hPa}$ ), we present green wave activity flux vectors and black geopotential height anomaly contours. The fuchsia vectors represent the divergent winds at the surface and around 300-hPa pressure level, and pink dashed arrows are indicative of rising air.

positive), it indicates that the EOF patterns are being expressed in the atmosphere; in other words, there is an "event" of that particular EOF (e.g., a PSA1 event). When the mean index values are positive, it indicates that the EOF patterns are being expressed as they appear in Fig. 2 (i.e., anomalies of the same sign), and when they are negative, the anomalies are of opposite sign. To show the spread within the event-day samples, we also present the median, 25th, and 75th percentile index values in Fig. 7. Our discussion of these results is thus guided by the periods during the extreme events where there are significant departures of the mean (and sample distribution) from zero.

Figure 7 indicates that there is only a weak expression of both SAM and PSA1 modes during wet extremes events in Queenstown. From around day -1 to day 10 of the wet event life cycle, the PSA2, IPA1, and IPA2 are expressed, as indicated by the higher index values over this period. Taking into account the spread in the results, one could say that between day -1 and day 5 of the wet event life cycle, around $75 \%$ of extreme wet events in Queenstown coincide with the expression of a positive IPA2 pattern in the atmosphere. Furthermore, over $75 \%$ of wet events coincide with a negative IPA1 between day 2 and day 9 and a negative PSA 2 between day 6 and day 10. The results suggest that there is expression of the EOF patterns during wet extreme events, and a visual comparison of the PSA2, IPA1, and IPA2 EOF patterns (Fig. 2) with the wet extremes composite wave train pattern in Fig. 4 further confirms these results. That is, from day -2 to day 1 , the high pressure system (i.e., positive anomaly) over New Zealand in the composite pattern (Fig. 4) coincides with a similar positive anomaly over New Zealand in the PSA2 pattern shown in Fig. 2. As the wet extreme events continue (from day 2 onward), the central Pacific blocking high moves to the east, and there is longitudinal expansion of the trough over New Zealand. The major anticyclone is now in the central South Pacific Ocean, and 

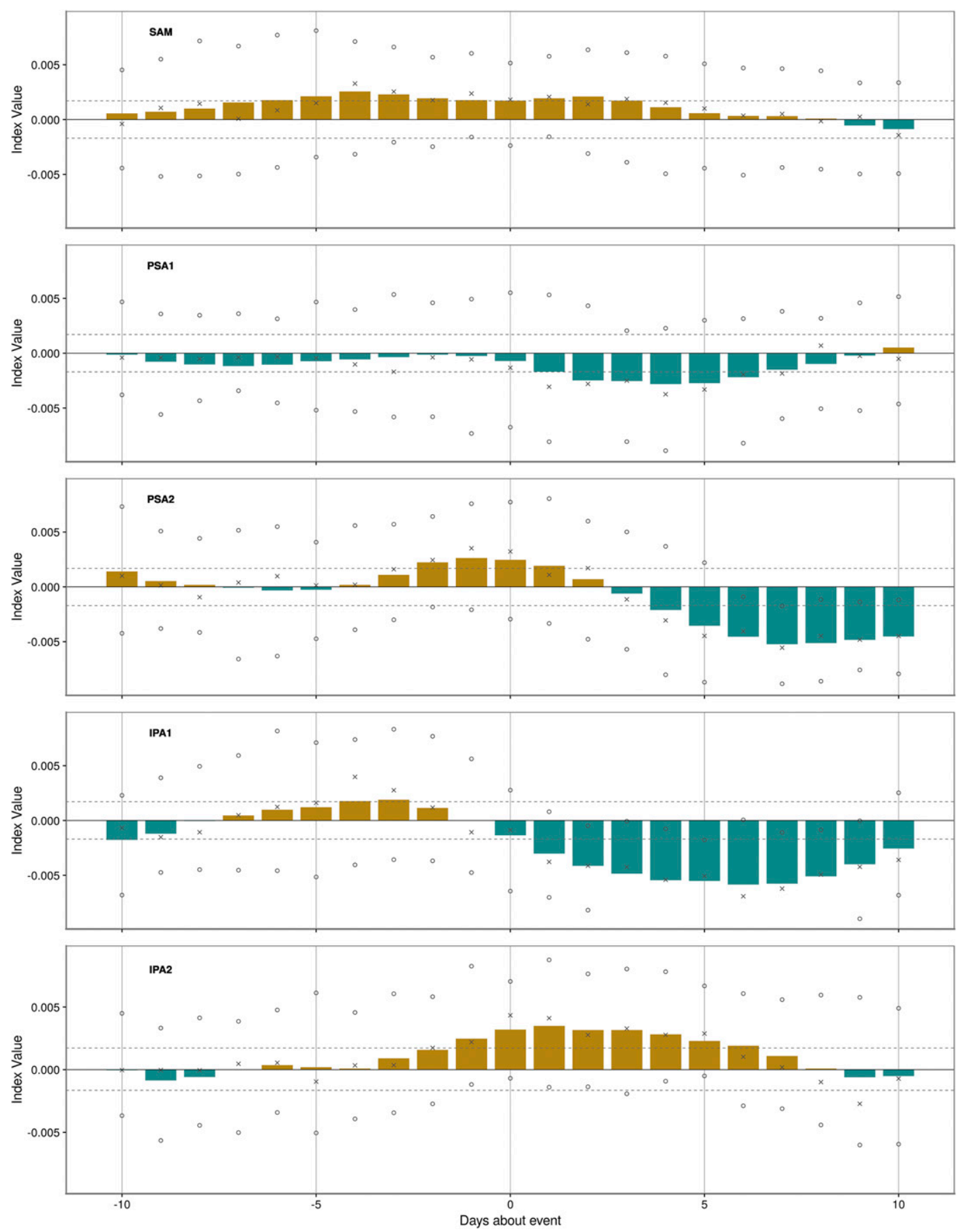

FIG. 7. Mean index values for the associated principal components of each EOF, calculated for each event day over the 43 Queenstown wet events. The yellow and green colors differentiate between positive and negative mean values, respectively. The gray crosses indicate the median index values. The gray circles represent the 25 th and 75 th percentile values. Where there are missing circles, it indicates that the percentile value exceeds the scale of the plot. The dashed gray lines indicate 5th and 95th percentile mean index values, calculated by randomly sampling each index dataset 43 times (as given by the total number of Queenstown autumn wet events) and calculating the mean index value from this sample. This process was undertaken 10000 times to form a distribution of mean index values. The 5th and 95th percentile values were then calculated from this distribution. Note that the number of times the index was sampled changed depending on the dry/wet event in question; see Table 1 for autumn event lengths for Queenstown/Fingal wet/dry. 


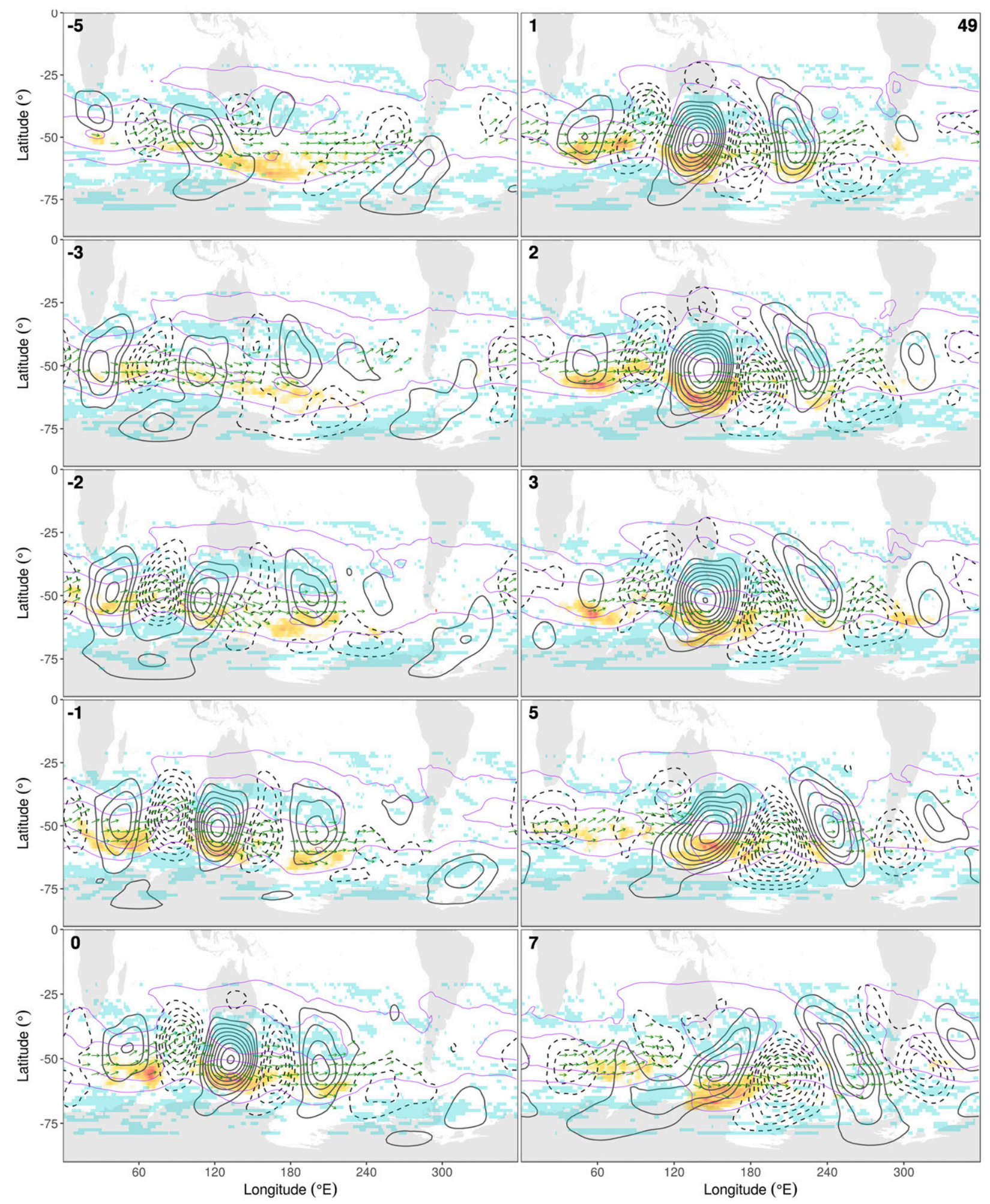

FIG. 8. As in Fig. 4, but for Queenstown dry events. 


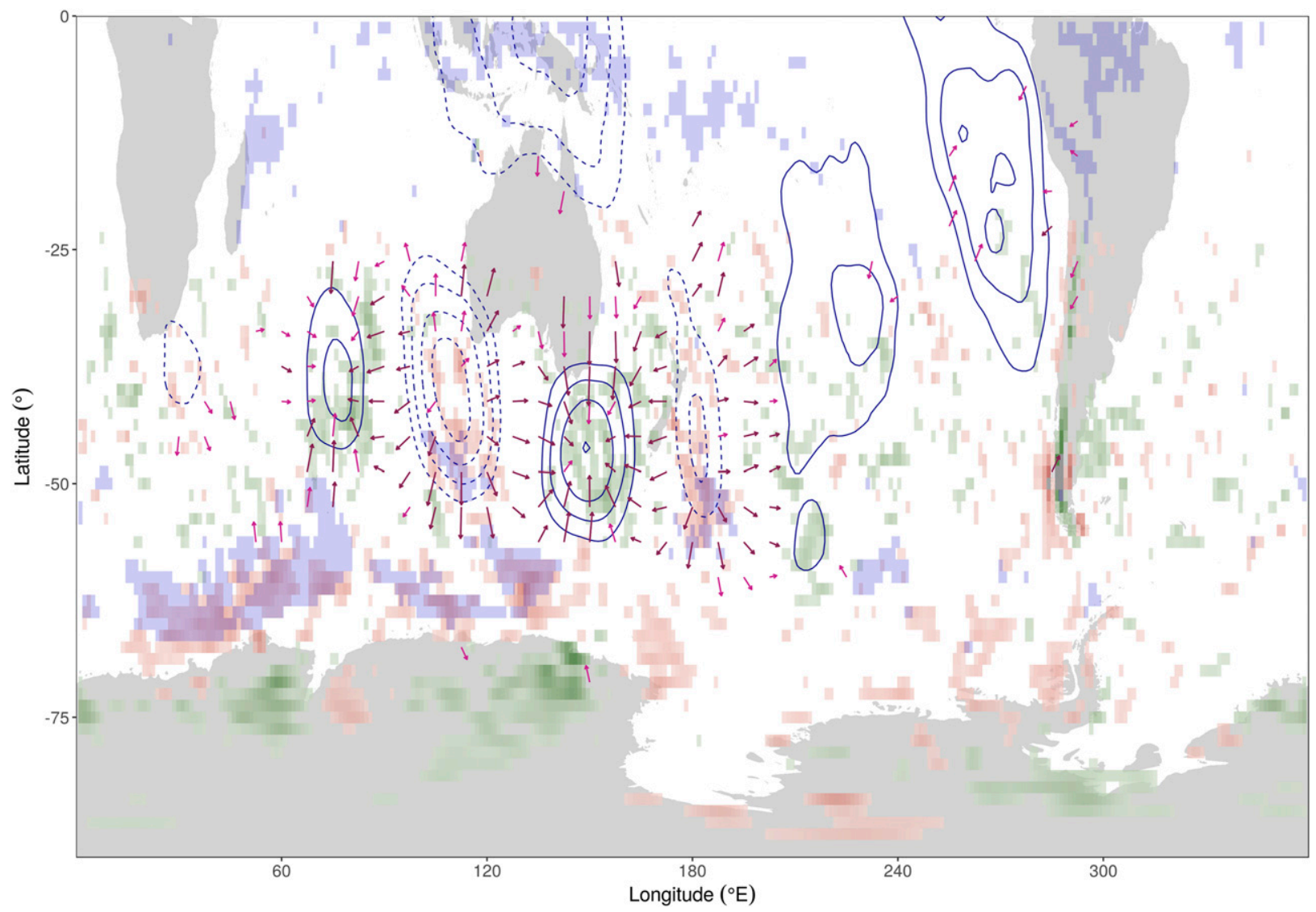

FIG. 9. As in Fig. 5, but for Queenstown dry events.

there is a second high pressure system across southern South America. These positive anomalies line up with the positions of troughs in the PSA2 pattern presented in Fig. 2, and hence we see in Fig. 7 that the PSA2 index is strongly negative from around day 6 to day 10. Figure 2 shows that the IPA1 pattern is characterized by alternating high and low pressure anomalies along the polar waveguide and, in particular, a high over Tasmania. In the wet extremes composite, there is similarly a persistent pressure anomaly over Tasmania; however, it is a negative anomaly (trough), which explains the negative phase of the IPA1. The IPA 2 pattern features alternating anomalies across the hemisphere but particularly in the Indian Ocean, and a key trough just south of Australia and blocking high around New Zealand. These systems line up with the trough around Tasmania and the high around New Zealand, evident in the wet extremes composite pattern, and explain why the IPA2 index is predominately positive over the event length.

\section{b. Dry extremes in Queenstown}

Figure 8 presents the composite atmospheric pattern associated with extreme dry events in Queenstown. A wave train is evident in the Indian Ocean at day -5 . This pattern becomes more coherent by day -2 , with the anomalies increasing in amplitude and spatial extent. At day 0 , a high pressure system shifts into place over Tasmania and persists in place until at least day 5, which corresponds with the median dry event length of 6 days. This blocking high interrupts the normal westerly conditions that provide topographically induced rainfall over western Tasmania. The block in turn promotes broadscale descent and a lack of rain over the region. This is confirmed in Fig. 9, where strong descent (upper-level convergence), positive velocity potential anomalies, and negative Rossby wave source values are evident over Tasmania. Throughout the event, the no-go zones are again far more extensive than in the climatological mean. The wave activity flux vectors again sit in the waveguide channel. The baroclinic instability is also increased relative to the climatological mean and again is primarily confined to the polar flank of the anticyclones.

Like in the wet extremes case, the dry extremes composite wave train pattern has hemispheric extent. There are clear similarities between the structures of the wet and dry extremes composites patterns, though they 

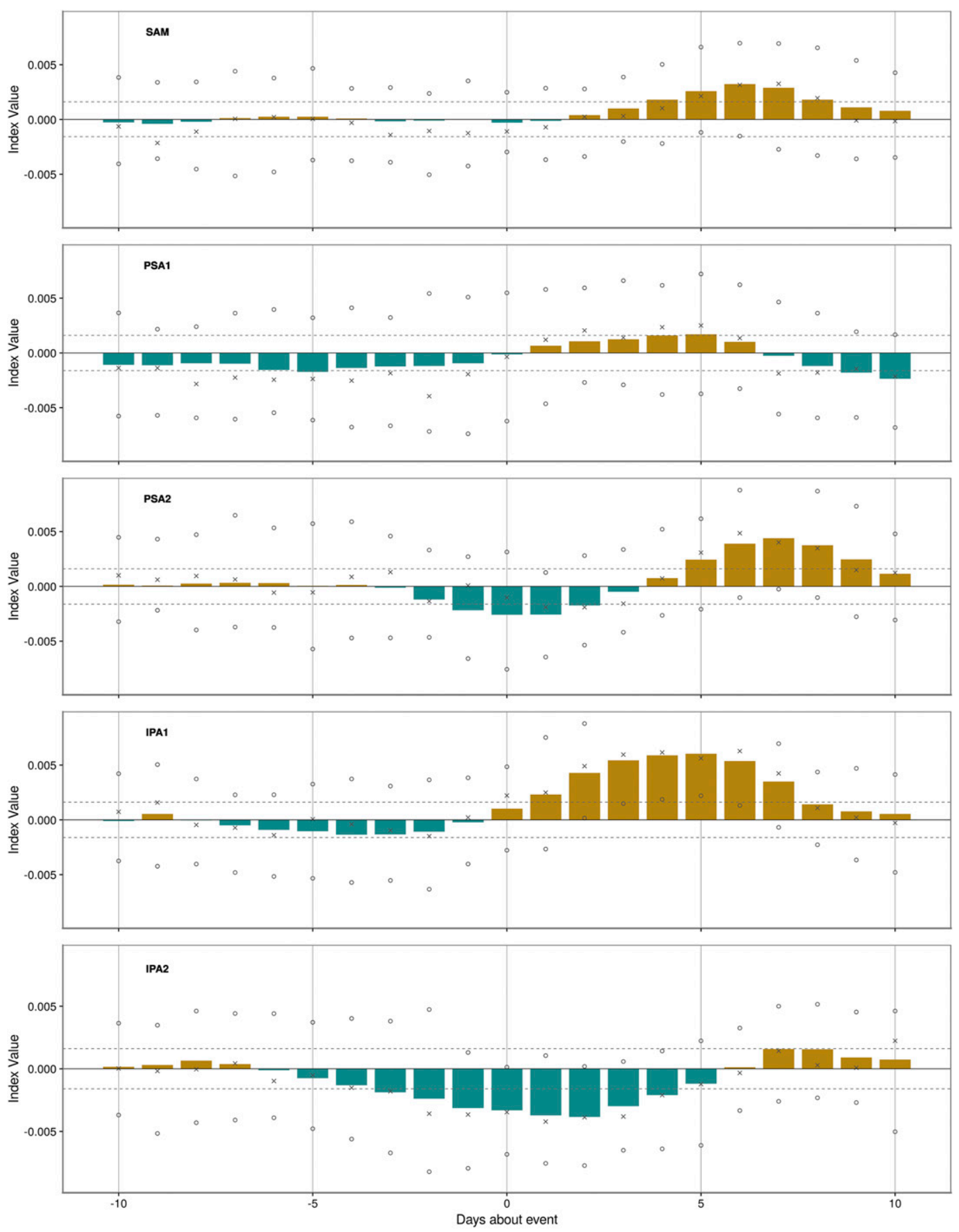

FIG. 10. As in Fig. 7, but for Queenstown dry events.

are of opposing phases. The wet extremes pattern appears to persist for longer, however, with the trough remaining in place over Tasmania at day 7 (Fig. 4), but in the dry extremes pattern, the corresponding blocking high over Tasmania has shifted east by day 7 , in concert with the whole wave train (Fig. 8). The difference in the persistence of the wave train patterns relates to the different median lengths of the wet and dry extreme events identified (Table 1), which in turn is related to their definitions (section 2).

The similar structures of the two composite patterns is further highlighted by comparing Figs. 7 and 10, which, for PSA2, IPA1, and IPA2, are almost identical but opposite in sign. This suggests that these EOF patterns 

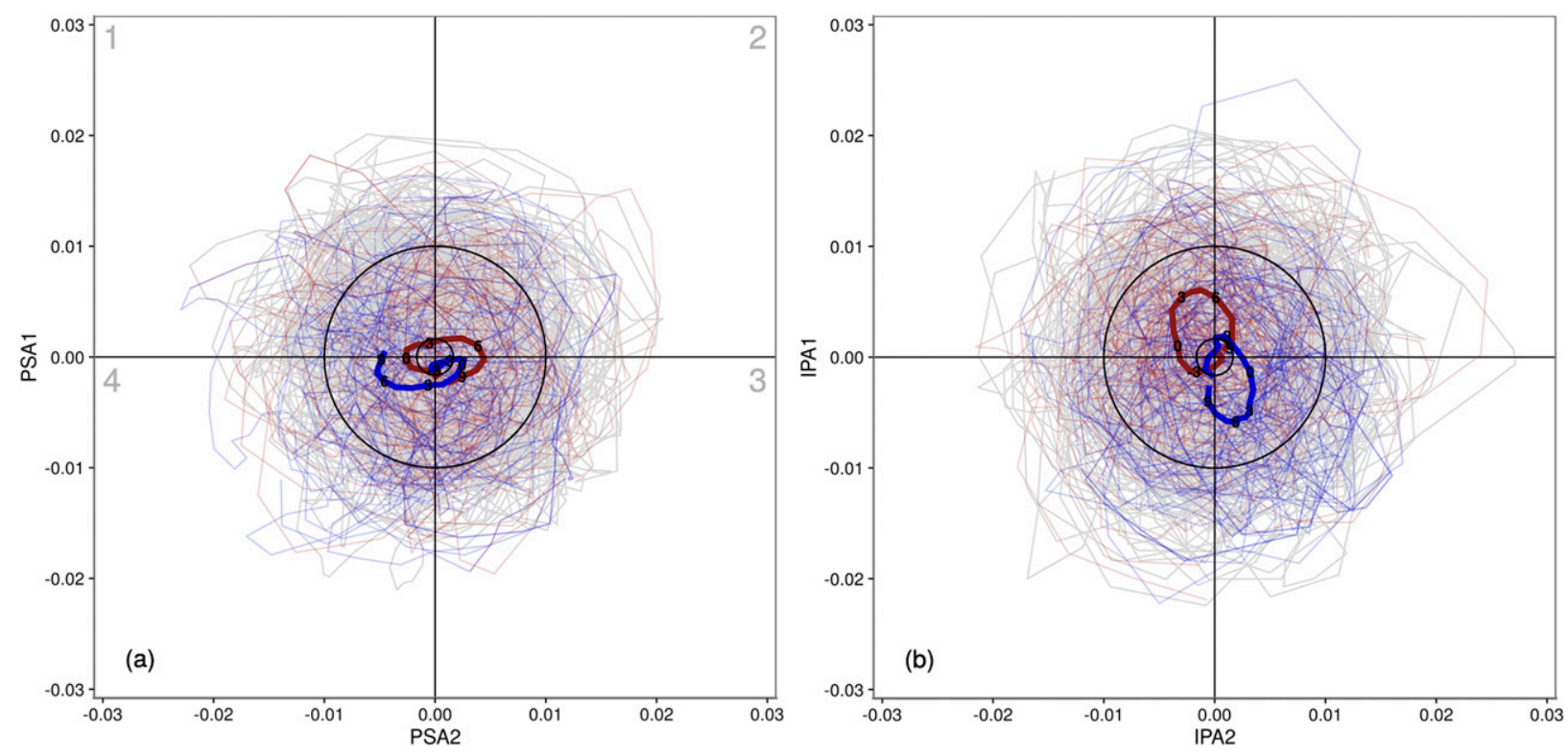

FIG. 11. Index phase plots for Queenstown wet events for (a) PSA1 and PSA2 indices. Thin red (blue) lines show PSA1 and PSA2 values for day -10 to day 10 of each dry (wet) event. Gray lines indicate PSA1 and PSA2 values for all autumn days, excluding wet and dry event days. The large black circle is drawn from the 5 th $(\approx-0.01)$ and 95 th $(\approx 0.01)$ percentile values for PSA1 and PSA2 indices. Thick red (blue) line shows the mean PSA1 and PSA2 values for dry (wet) events for day -10 to day 10 . These values are also shown for each index in the bar plots presented in Fig. 7 for wet events and Fig. 10 for dry events. Days $-3,0,3,6$, and 9 indicate the direction of propagation. The small black circle is drawn from the 5th- and 95th-percentile values from the distribution of mean index values for wet and dry events. These values are also shown for each index as the dashed gray lines in Fig. 7 for wet events and Fig. 10 for dry events. For wet events, the percentile values are $\approx \pm 0.0017$ and for dry events $\approx \pm 0.0016$ for all indices (including IPA 1 and IPA2), and so the circle is drawn through 0.00165 . Quadrants 1, 2, 3, and 4 are labeled. (b) As in (a), but for IPA1 and IPA2.

are similarly expressed, at least $75 \%$ of the time, during Queenstown dry events. Comparison of the dry extremes pattern in Fig. 8 and EOFs in Fig. 2 confirms the association. For example, the IPA1 pattern (Fig. 2) features alternating anomalies in both the Indian and Pacific Oceans, including a high over Tasmania, which aligns with the structure of the dry events wave train pattern. We note that the expression of the EOF patterns during Queenstown dry events "tapers off" earlier than for the wet events. For example, expression of the IPA1 ceases around day 7, but for the wet extremes, it continues to day 10 . This behavior again reflects the longer persistence of the wet extremes events, compared with the dry events.

Figures 7 and 10 clearly show that the EOF patterns are expressed during wet and dry extreme events in western Tasmania. Further exploration of the relationship between the EOF and wet/dry extremes composite patterns is undertaken in Fig. 11. Here, we plot the PSA and IPA index values for all autumn days across the 1958-2016 period (thin gray lines) and indicate in thin blue lines when those days fall on day -10 to day 10 of a wet event and in thin red lines for a dry event. We assess PSA1 and PSA2 (Fig. 11a) and IPA1 and IPA2 (Fig. 11b) together because they are paired modes of variability (section 1).
Where values sit outside the large black circle, it indicates they are greater than the 5th and 95th percentile index values and are therefore relatively extreme values, and hence the PSA/IPA patterns are being well expressed on these days. We also present the mean index values (i.e., the same as those presented in Figs. 7, 10) for wet events with the thick blue lines and dry events with the thick red lines, and where these values exceed the small black circle, they represent extreme mean values. Figures 7 and 10 indicate that the PSA and IPA patterns have preferred phases (i.e., negative and positive) that change during the extreme events and that this preferred phase reaches a maximum expression (maximum index value) at different stages of the wet/dry extremes. This feature is further highlighted in Fig. 11, where for IPA1 and IPA2, the bulk of thin blue lines (indicating wet events) sit in the negative IPA1 and positive IPA2 quadrants (quadrant 3 ). The mean values (thick blue line) additionally confirm this tendency. For dry events (thick red line), the opposite is the case, whereby quadrant 1 is favored (positive IPA 1 and negative IPA2). For the PSA, during wet events quadrant 4 is favored, and for dry events quadrant 2 is favored.

The phase plots additionally show the progression of the PSA and IPA during the wet and dry events. In the 
early onset period of the events, the patterns are not strongly expressed (i.e., the index values are close to zero), but as the events start, the patterns progress through different phases. For example, at day -3 of dry events (thick red line in Fig. 11b), both IPA patterns have index values close to zero. By day 0 , the negative phase of IPA2 is expressed, but IPA1 remains around zero. At day 3, both IPA1 and IPA2 are at their maximum expressions. By day 6 , IPA2 has returned to zero, but the positive phase of IPA1 is still expressed. The event decays, and IPA1 also returns toward zero. Similar observations can be made for the wet events and for PSA1 and PSA2 (Fig. 11a). Mo and Higgins (1998) have similarly shown that the atmospheric flow in the Southern Hemisphere has a tendency to evolve from PSA1 to PSA2, becoming stationary for periods of time before propagating eastward again.

Figure 11 hence further confirms the relationship between the EOF patterns and wet/dry extremes. However, the question remains as to whether every expression of the EOF patterns relates to wet and dry extremes in western Tasmania (e.g., does western Tasmania experience a wet/ dry extreme every time the PSA2 is expressed?). The spread in the index values presented in Figs. 7 and 10 suggests that this is not likely the case, though we can further address this question by referring to the thin gray lines in Fig. 11, which indicate nonextreme event days. From both Figs. 11a and 11b, it is clear that there are nonevent days that record higher PSA1, PSA2, IPA1, and IPA2 index values than wet/dry extreme event days. This indicates that expression of the EOF patterns in the atmosphere does not always mean that an extreme wet/dry event, at least by the extreme definitions used here, will occur in western Tasmania. Likewise, though the composite patterns in Figs. 4 and 8 indicate the association between wave trains and wet/dry extremes in Queenstown, the noise in these patterns (discussed in appendix) suggests that these extremes may not always be associated with a large-scale wave train pattern.

\section{c. Wet extremes in Fingal}

The composite circulation for wet extremes in Fingal is presented in Fig. 12. The polar waveguide channel is again demarked by the no-go zone and wave activity flux vectors, and baroclinic instability is focused in the poleward flank of the high pressure systems, particularly the blocking high south of Australia. This block persists for around 5 days in the polar jet, "cradling" a low pressure system, which is cut off from the polar storm track. This cutoff low is capable of delivering persistent high rainfall over the eastern half of Tasmania, and indeed, this synoptic feature is known to bring high rainfall to southeastern Australia (e.g., Pook et al. 2006, 2010; Risbey et al. 2013a; Pepler et al. 2014). The high rainfall associated with this atmospheric pattern is evident in Fig. 13, which corresponds to high-amplitude negative velocity potential anomalies across eastern Australia, divergent winds, and positive Rossby wave source. The "cradling" block reduces in amplitude by day 5 , in concert with a strengthening of a high pressure system and downstream trough around South America. The nature of the wave train pattern that brings extreme rain to Fingal differs to the modes identified for Queenstown wet/dry events in that it is expressed as a propagating wave train as opposed to a circumglobal pattern. That is, a wave train sets up in the Indian Ocean in the wet event onset phase, shifts into the Australian region during the event, and, as the event matures and decays, moves into the Pacific Ocean (i.e., the higher-amplitude anomalies are in the Pacific Ocean at this time). Figure 14 also shows that there is expression of the EOF patterns during Fingal wet events, with strong expression of the IPA2 around day -2 to day 0 , IPA1 from day 0 to day 3 , shifting to PSA2 from around day 1 to day 5, and then PSA1 from around day 3 to day 10 .

\section{d. Dry extremes in Fingal}

Dry events in Fingal can be quite long-lived, with a median length of nearly 2 weeks and a maximum event length of 42 days (Table 1 ). The attribution of dry events in locations like Fingal, where the majority of days (e.g., $61 \%$ in the case of Fingal) are dry, is difficult. Long sequences of dry days could be the result of essentially random synoptic sequences with no relationship to any larger-scale dynamical mode, or could incorporate a range of dynamics at different time scales. In that event, composites over dry events would generally yield little or no coherent largescale signature. On the other hand, the long dry events may be longer-lived, not by chance, but because there are longlived dynamical processes that condition Fingal to be free of rainfall for an extended period. If such dynamical processes were coherent and consistent for these extreme dry events, we may see their signature in the event composites. Even in this case, we would expect some imprecision in the expression of such large-scale atmospheric patterns (for dry events, as we define them) because the onset of any dynamically induced long-lived dry period will, by chance, include a dry day before the dynamically relevant period. That is, the onset of such dry events will typically include a day or so, by chance, that does not have a relationship to large-scale patterns and then a sequence of days that are conditioned by the larger scales.

The composites for Fingal dry events are shown in Fig. 15 and provide some resolution of these questions. By day -3 and beyond, there is a coherent large-scale mode apparent in the composites, which the Monte Carlo significance test presented in the appendix suggests we are unlikely to obtain 




FIG. 12. As in Fig. 4, but for Fingal wet events. 


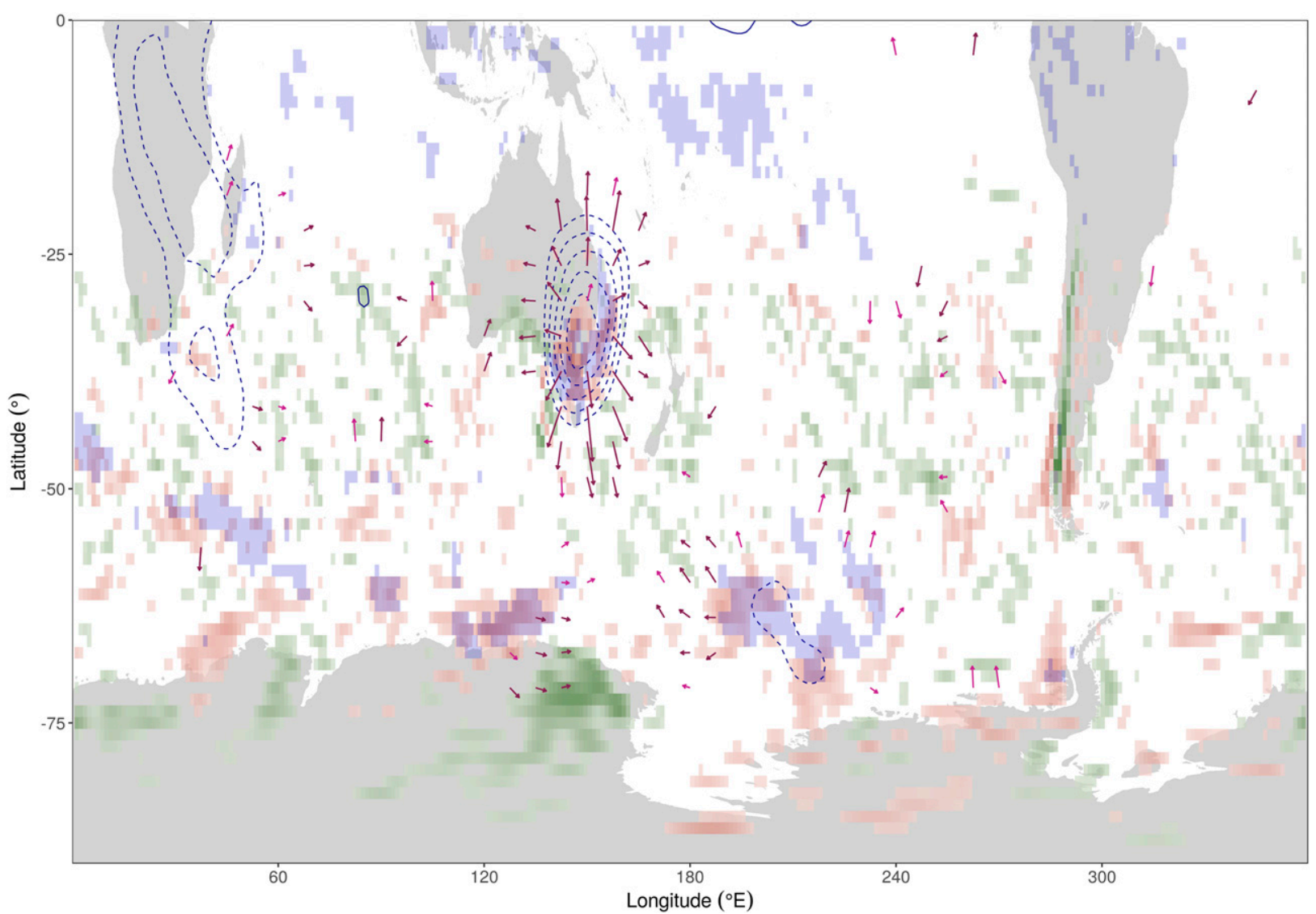

FIG. 13. As in Fig. 5, but for Fingal wet events.

simply by chance. From this, we infer that the longer-lived dry events are not simply the statistical result of purely random synoptic sequences. Rather, there is a large-scale pattern that typically, acknowledging that there is some spread in event samples (appendix), conditions Fingal to undergo long-lived dry events. While one might have imagined that there were many different ways for a location like Fingal to be dry, there appears to be a consistent way for Fingal to be dry for an extended period of time, at least relative to the way in which we have defined dry events here.

The structure conditioning Fingal extreme dry events is a wave train in the polar waveguide (Fig. 15). However, in contrast to the Queenstown wet/dry and Fingal wet events, there is little coherency in the Indian Ocean during the onset stage of the event. Instead, a blocking high is evident in the Pacific Ocean near South America around day -5 and appears to prevent the eastward propagation of the flow, allowing the organization a wave train spanning the Pacific Ocean by day -3 . Although a trough sits around Tasmania on day 0 , there is weak convection over eastern Tasmania, as indicated in Fig. 16, with positive velocity potential anomalies, negative Rossby wave source, and convergent winds. By day 2, a high sets up around Tasmania and persists in this region during the event. This apparent delay to the start of the dry events is consistent with the point made above that the dynamical mode-induced dry period will, by chance, include a day or so that is also dry that does not relate directly to the large-scale dynamics. This means that the event start time and, consequently, the onset phase, is not particularly well defined. Nonetheless, the composites reveal a coherent structure spanning the Pacific Ocean sector during these events. This atmospheric structure is reminiscent of the PSA pattern, which is confirmed in Fig. 17, where the PSA1 is clearly expressed. This expression occurs particularly around day 7 to day 15 , where around $75 \%$ of Fingal dry events coincide with a positive PSA1. The PSA pattern is the most long-lived waveguide mode in the Southern Hemisphere (O'Kane et al. 2017), and thus it is consistent that this mode is expressed during these long dry events.

\section{Discussion and conclusions}

The analysis presented here indicates that wet and dry extreme rainfall events at locations in western and eastern 

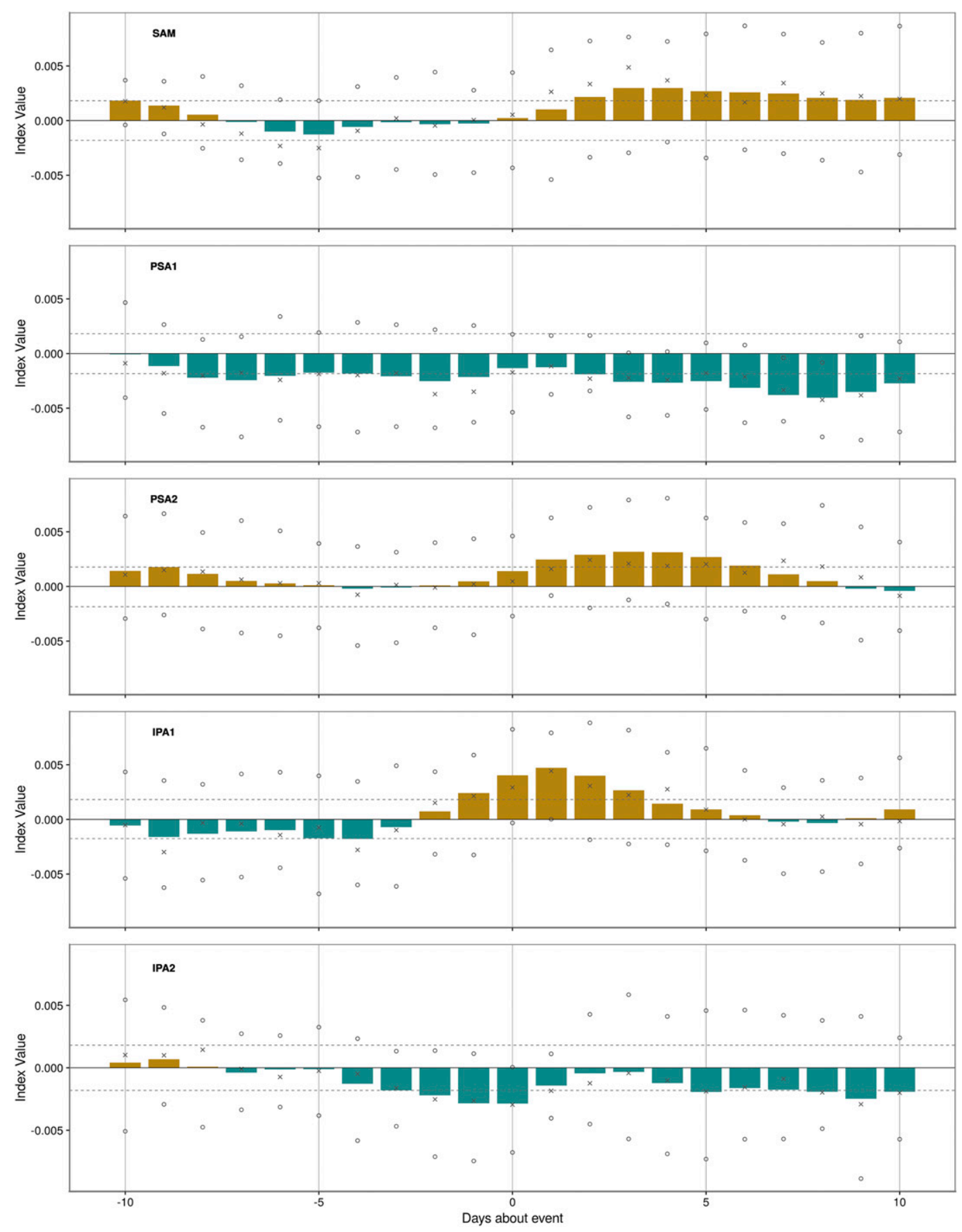

FIG. 14. As in Fig. 7, but for Fingal wet events.

Tasmania typically occur in association with coherent large-scale wave train patterns in the atmosphere. The wave trains are expressed primarily in the polar jet waveguide channel, where baroclinic instability and wave activity flux have maximum values. During wet/dry extremes, the waveguide channel is well defined and has hemispheric extent, which contrasts with the climatological mean wave channel, which has limited longitudinal extent. By implication, the wave train patterns are well expressed when the wave channel is well defined and spans much of the hemisphere. The blocking high pressure systems are prominent features of the composite wave train patterns during the extreme events and are marked by strong baroclinic instability throughout the event life cycle. 


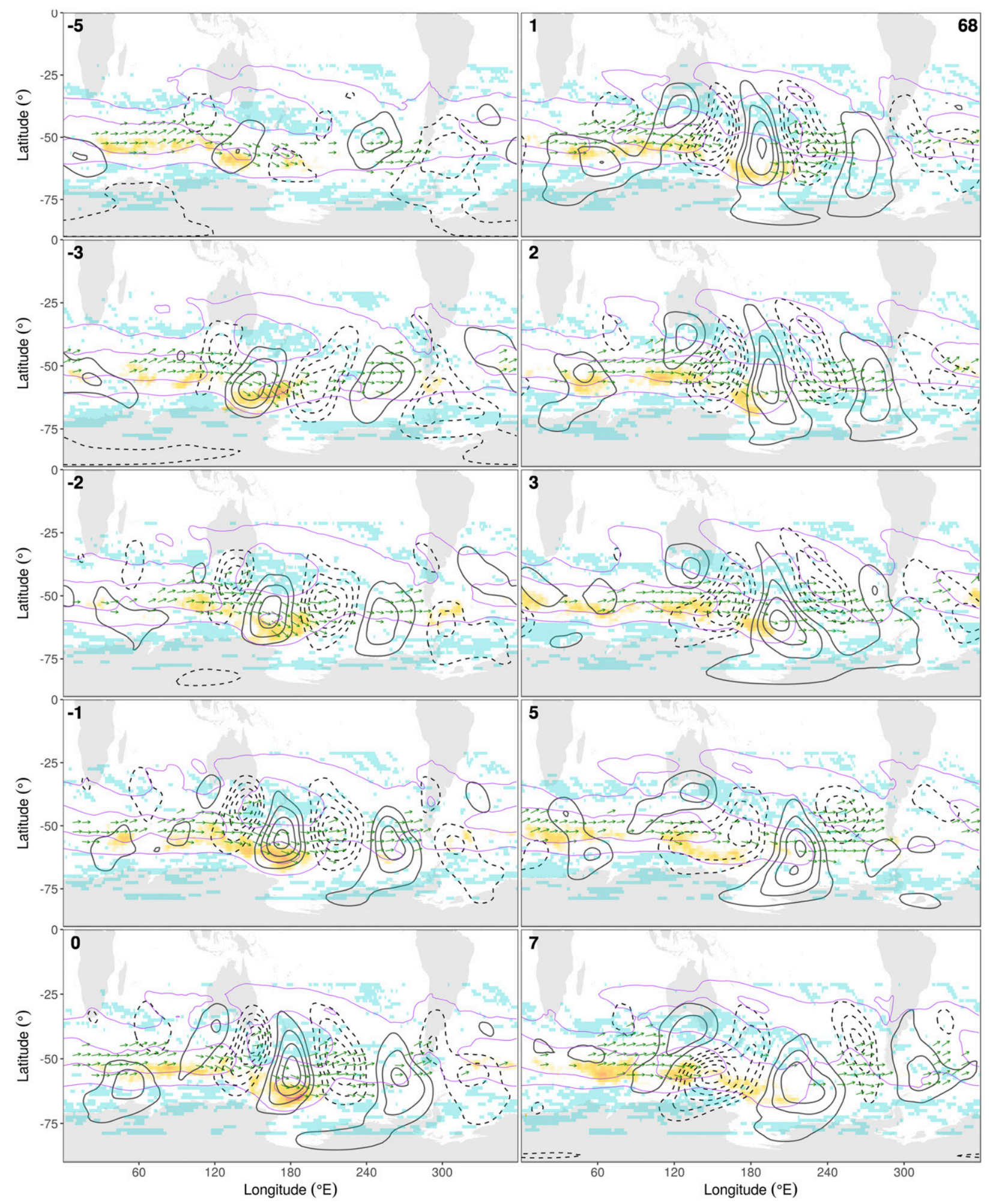

FIG. 15. As in Fig. 4, but for Fingal dry events. 


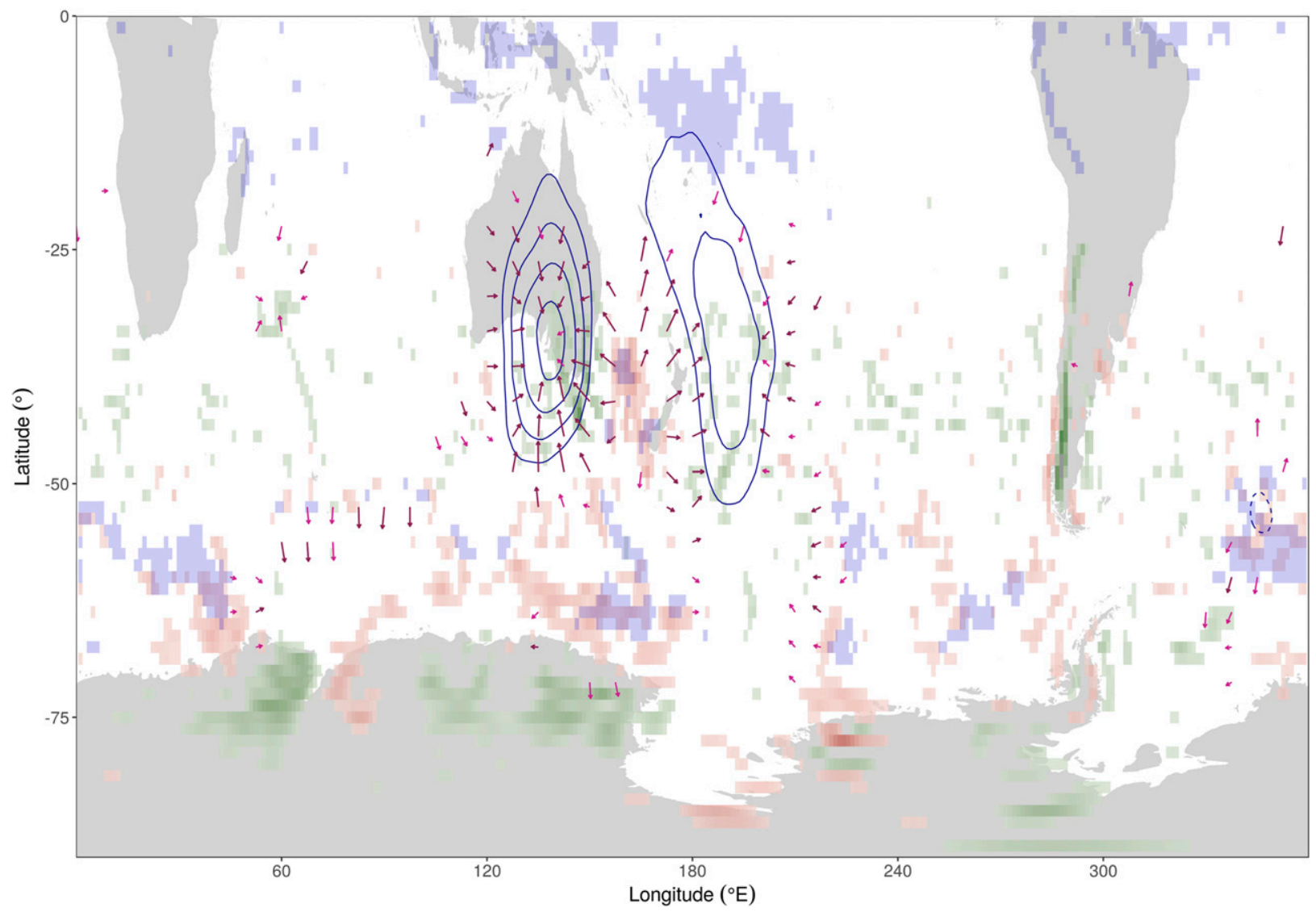

FIG. 16. As in Fig. 5, but for Fingal dry events.

In regards to the specific atmospheric structure associated with each of the four event types, we first summarize the synoptics of each case. For Queenstown wet events, a blocking high sets up in the central Pacific, which allows a persistent long-wave trough to set up over Tasmania. The trough provides for consistent amplification of short wave features over Tasmania during the wet event. During Queenstown dry events, a block sets up directly over Tasmanian longitudes, which interrupts the normal westerly stream conditions that provide topographically induced rainfall over Tasmania. The high also ensures that there is broadscale descent over Tasmania and therefore little or no rainfall. In Fingal wet cases, there is a dipole structure consisting of a block cradling a cutoff low, which sets up in Tasmanian longitudes. The cutoff low delivers high rainfall over the eastern Australian region. For Fingal dry events, a high is established around Tasmania, which favors dry conditions in the region.

We now summarize the large-scale dynamics associated with these events in the Hovmöller plots presented in Fig. 18. The contours are filtered to show significant geopotential height anomalies at a latitude of $-55^{\circ}$, relative to the 5th and 95th percentile geopotential height anomalies determined through Monte Carlo analysis. The contours clearly demarcate the wave train patterns relevant to each of the wet and dry extremes that were discussed in section 3. More specifically, wet and dry extremes in Queenstown exhibit circumglobal wave train patterns, but of opposite phase (Figs. 18a,b). In both cases, the event is preceded by an organized wave train in the Indian Ocean sector. From the time the event starts (and for the duration of the event), the wave train patterns are expressed over the entire hemispheric domain and are relatively quasi-stationary. During Fingal wet extremes, there is a propagation of the wave train from west to east before and during the event. This is shown in Figs. 12 and 18c, where the coherent wave train appears in the Indian Ocean prior to the event, establishes the blocking high/cutoff low dipole over Tasmania that initiates the event (where the block is a part of the wave train in the polar jet waveguide), and then moves into the Pacific region as the event matures. Unlike the other events, Fingal dry extremes appear to have no precursor in the Indian Ocean, only in the Pacific Ocean (Fig. 15). The Hovmöller plot in Fig. 18d additionally shows that from around day 2 , the wave train becomes quasi-stationary, particularly the high around $180^{\circ}-240^{\circ}$ and upstream 

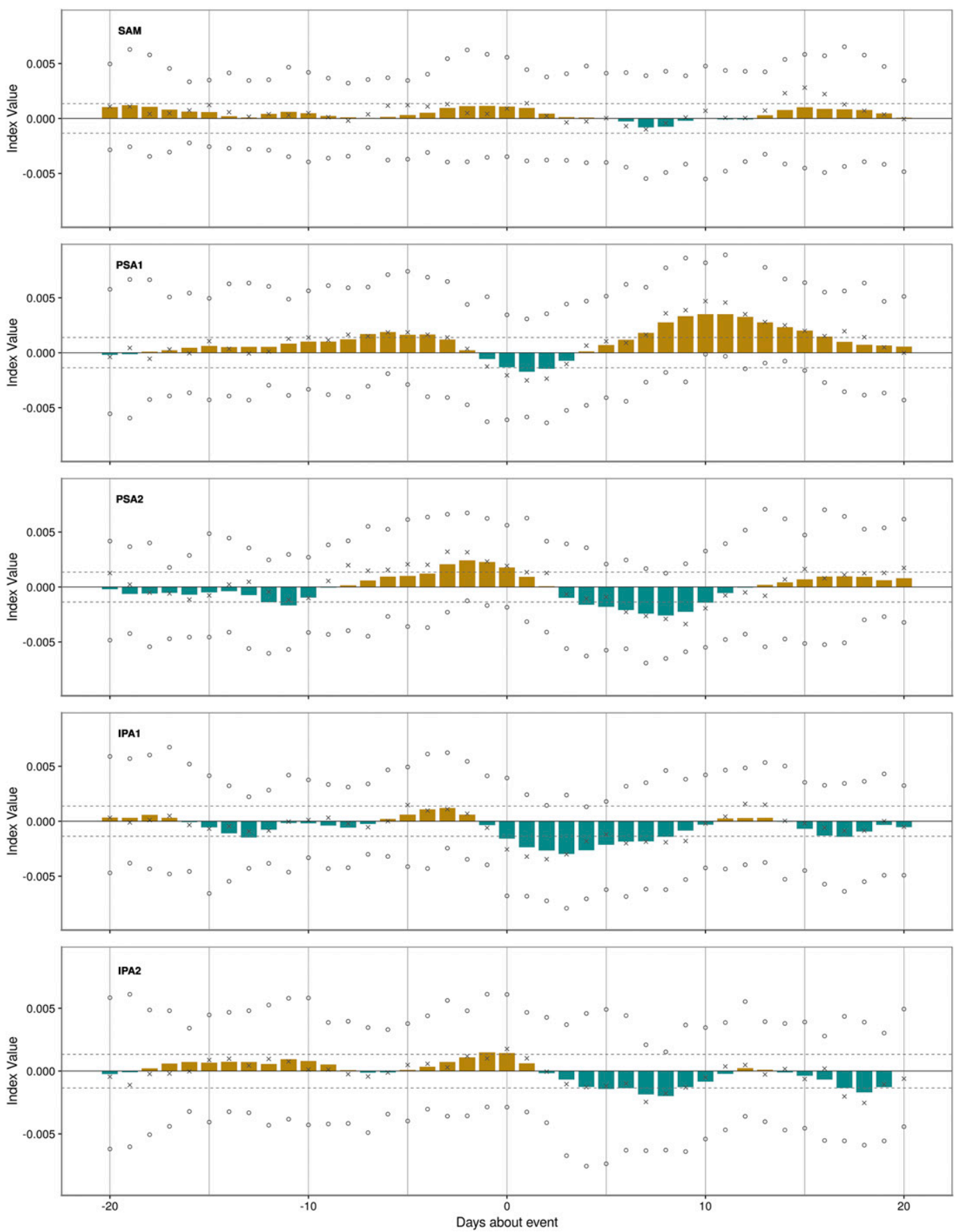

FIG. 17. As in Fig. 7, but for Fingal dry events. Given the long-lived nature of Fingal dry extreme events, the plots have been extended to day 20 .

trough. The composite pattern indeed very closely resembles the PSA in structure and persistence behavior (e.g., Mo and Higgins 1998; O'Kane et al. 2017). However, as discussed in section 3 (and the appendix), there is some "noise" in the results, which suggests that wet/dry extremes in Tasmania may not always occur when the atmosphere expresses a coherent wave train pattern. An investigation into intraevent variability across extreme events may assist in refining the relationship between large-scale atmospheric processes and extremes in Tasmania and may form the basis of a future analysis.

Nonetheless, the attribution of rainfall extremes in Tasmania to wave trains provides some information about their predictability, which may be of particular interest for 

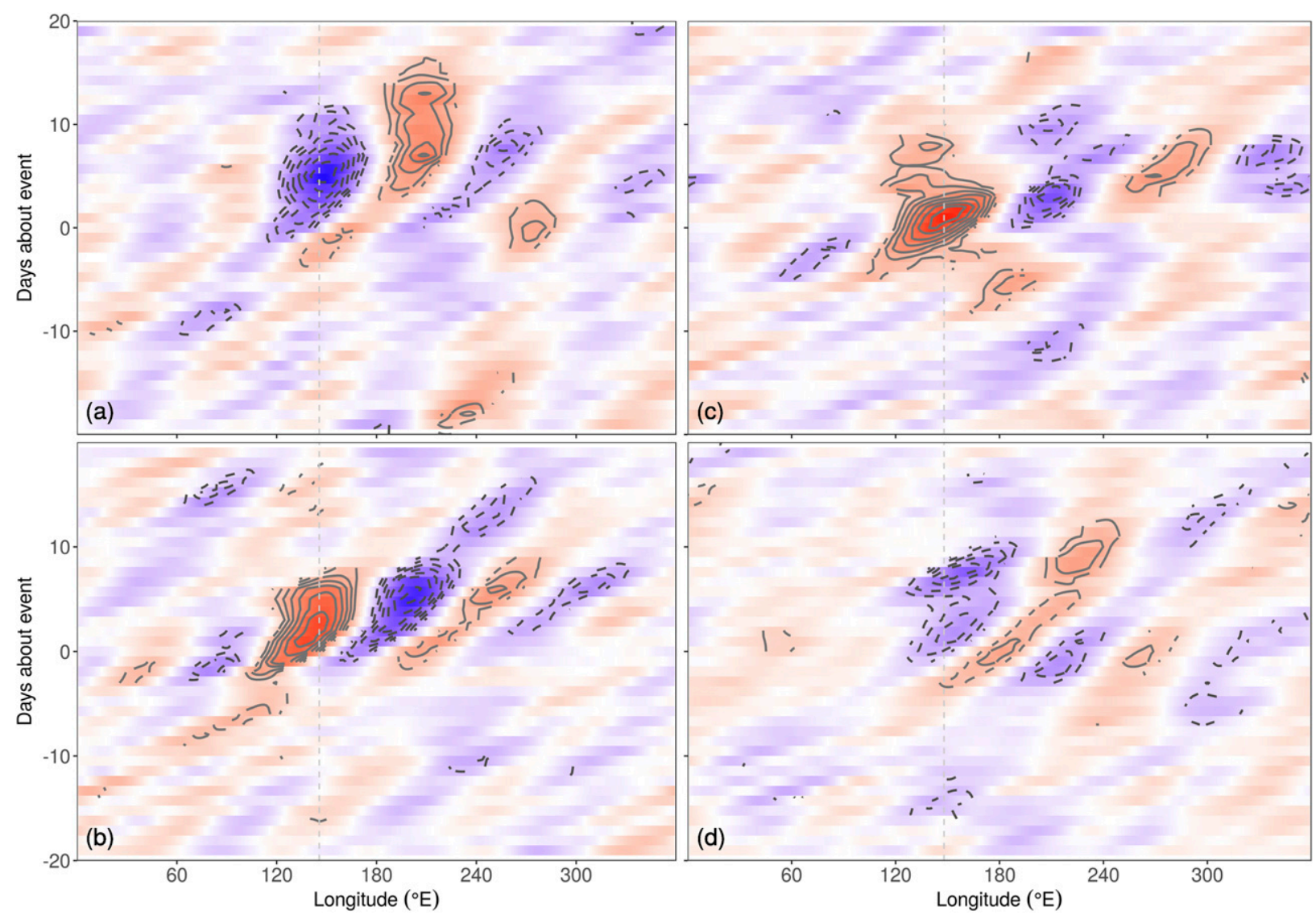

FIG. 18. Hovmöller plots of geopotential height anomalies at $-55^{\circ}$ latitude for (a) Queenstown wet, (b) Queenstown dry, (c) Fingal wet, and (d) Fingal dry extreme events for day -20 to day 20. Blue (red) shading indicates negative (positive) anomalies ranging from -150 to $150 \mathrm{~m}$. The contour lines indicate where the mean geopotential height anomalies are greater than the 95th or less than the 5th percentile mean anomalies, where the 95 th and 5th values are calculated as per the method described in the appendix. Contours are filtered to only show values $>15$ or $<-15 \mathrm{~m}$, with contours every $15 \mathrm{~m}$. The gray dashed line indicates the longitude of Queenstown and Fingal.

water resources planning of the hydropower storages in western Tasmania. That is, for western Tasmania, the coherent wave train structure in the Indian Ocean $\approx 5$ days prior to the wet and dry events (i.e., before the establishment of the key blocking high pressure system) gives us a basis, because of the large-scale nature of the atmospheric processes at play, for predictability. The patterns identified are intrinsic features of the atmosphere, and therefore we also have a bound, in regards to potential lead time, for predictability. This bound (identified here between 3 and 7 days) is consistent with earlier theoretical work on blocking onset and decay (Frederiksen 1982, 1983; O'Kane and Frederiksen 2008). These findings may help in evaluating and interpreting forecast models in their ability to forecast the atmospheric structures relevant to rainfall extremes in Tasmania and other locations. More generally, the insights regarding the different wave train forms and their relationship to rainfall extremes have implications for extreme event (rainfall extremes, heat waves, frosts, etc.) attribution in other regions around the globe.
Acknowledgments. This work was supported by the Decadal Climate Forecast Project and DIGISCAPE Future Science Platform at CSIRO and HydroTasmania. C. Tozer would like to thank Tom Remenyi (Antarctic Climate and Ecosystems Cooperative Research Centre) and Mike Sumner (Australian Antarctic Division) for providing software support. We are grateful to the editor for providing sound guidance. Additional information regarding the Japanese 55-yr Reanalysis data used can be found at http://jra.kishou.go.jp/JRA-55/.

\section{APPENDIX}

\section{Assessment of the Significance and Spread of the Composite Geopotential Height Anomalies}

In this appendix, we test the significance of the composite geopotential height anomaly patterns presented in Figs. 4, 8, 12, and 15. We do this by performing an "out of sample" Monte Carlo significance test. That is, we 
compare the event-day mean geopotential height anomalies to the 5th and 95th percentile mean geopotential height anomalies for all nonevent days (i.e., out-of-sample days) in autumn over the 1958-2016 period. The 5th and 95 th percentile mean anomalies were calculated by randomly sampling, from a subset of days that do not include the respective event days, the geopotential height field the same number of times as there are events (e.g., 43 times in the case of Queenstown wet events). This process was undertaken 1000 times so that a distribution of mean geopotential height anomalies was produced for each grid point across the Southern Hemisphere. From this distribution, the 5th and 95th percentile values were calculated. The mean anomalies calculated for day -10 to day 10 of the extreme event in question can then be compared to the 5th and 95th percentile values. Where the event anomalies are either less than the 5th percentile values or greater than the 95th percentile values, it suggests that the event-day anomalies are more notable. We present these results in the Hovmöller plot in Fig. 18, where the contours indicate where the mean anomalies are greater than the 95th and less than the 5th percentile values. For a different view, we present Fig. A1, which indicates in bold the mean geopotential height anomalies for day 2 of wet and dry events in Queenstown and Fingal that are significant relative to the 5th and 95th percentile values. Day 2 was selected, as all events have commenced by this day, noting that the Fingal dry event commencement is delayed relative to the other events (as discussed in section 3d). Importantly, both Figs. 18 and A1 show that the ridges and troughs that form part of the wave train pattern are significant. That is, it is not just the synoptic structures (e.g., the trough over Tasmania in the case of Queenstown wet events) that are notable, but all structures in the wave train, which suggests that the wave train pattern is not just a random feature of the composites. Ultimately, in general, we show that by chance, we are unlikely to obtain the high-amplitude organized wave train structure of geopotential height anomalies we identify around the Queenstown and Fingal wet and dry events. Note that we also undertook the Monte Carlo sampling analysis in our assessment of the activity of the SAM, PSA, and IPA patterns during the extreme events, as described in the caption of Fig. 7. As discussed in section 3, the results provide strong evidence that the different wave train patterns are expressed during extreme events in Queenstown and Fingal.

We additionally assess the variance within each eventday sample by calculating the signal-to-noise ratio. While this is not a test of significance of the composite patterns, it gives an indication of the spread in the composite samples. A higher ratio indicates that most of the anomalies in the sample (e.g., all 43 anomaly values for day 2 of Queenstown wet events) are close to the mean sample value. The smaller the ratio, the greater the spread within the sample. We present the signal-tonoise ratio for day 2 of each event in Fig. A2, with ratios greater than 0.5 highlighted in light green and values greater than 1 in dark green. Again, a ratio greater than 1 is not a level of significance, but an indicator that there is less spread in the event-day sample. The analysis shows that the highest signal-to-noise ratios occur where there are high-amplitude geopotential height anomalies (e.g., in the trough over Tasmania for Queenstown wet events, the blocking high over the same region during Queenstown dry events, or the cutoff low/block dipole in Fingal wet events). The signal-to-noise ratio is lower at other structures within the waveguide, which suggests that there is noise in the extreme event composite patterns in these regions. We identify four key issues that may be contributing to noise in the composite: small sample size, misalignment of individual structures, ambiguous event definition, and lack of a coherent signal. We discuss these in detail below.

A key factor affecting composite analyses is small sample size, an inevitable issue facing any assessment of extreme events, which, by definition, are relatively infrequent. With a small sample size, there is more chance that a coherent signal will not be found or that a single event (or small number of events) could bias the composite pattern. In other words, the composite pattern would be representative of only a few events and not the full sample. With a larger sample, however, the influence of any individual events would be filtered out. Given this, we also calculated the signal-to-noise ratio for the full-year analysis and present it in Fig. A3 for day 2. A comparison of Fig. A2 (autumn) and Fig. A3 shows that despite the larger sample sizes of the full-year analysis, the signal-to-noise ratio did not increase. We suggest that this is because the full-year analysis incorporates all season variability, which, although subtle (section 3), adds noise to the full-year composites. This does not provide a solution to the potential small sample size of autumn extremes investigated here, and it is indeed difficult to overcome the small sample size issue in any composite analysis. The Monte Carlo analysis described above, however, goes some way to providing confidence that the patterns identified from a small sample, such as in our study, are significant.

Beyond sample size, a further issue potentially affecting the signal-to-noise ratio is the possible intraevent spatial variability in the structures that form part of the wave trains. That is, the individual structures in the wave train patterns, particularly those remote to Tasmania, may be slightly misaligned between events, which could 


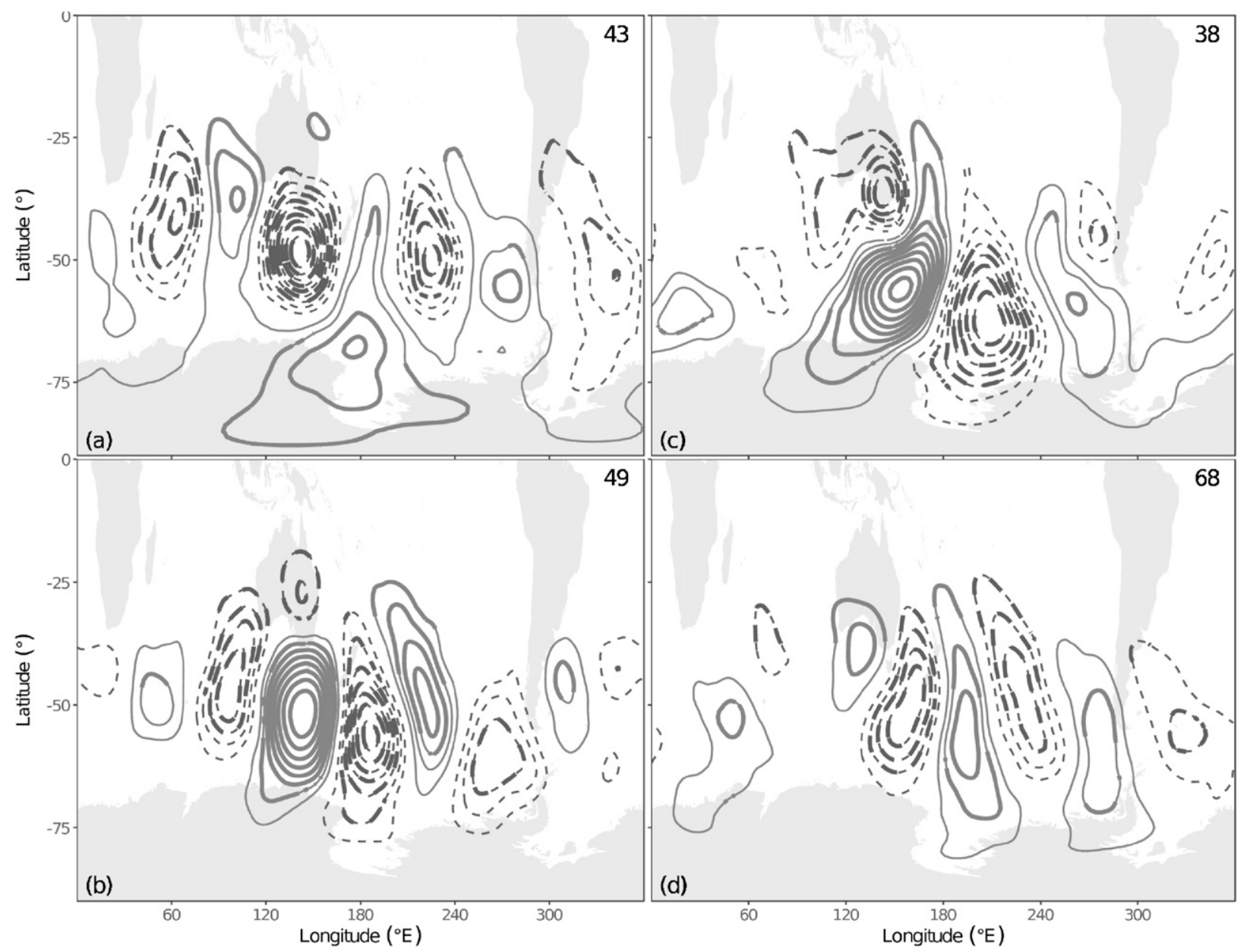

FIG. A1. Mean negative (dashed contours) and positive (solid contours) geopotential height anomalies for day 2 of (a) Queenstown wet, (b) Queenstown dry, (c) Fingal wet, and (d) Fingal dry events. The geopotential height anomalies presented here are the same as those presented in Figs. 4, 8, 12, and 15 for day 2. Bold sections of the contour lines indicate where the mean geopotential height anomalies are greater than the 95th or less than the 5th percentile mean anomalies, where the 95th and 5th percentile values are calculated as per the method described in the appendix.

result in their cancellation during the compositing process and therefore the degradation of the wave train signal and reduction of the signal-to-noise ratio. This may be due to variability in the start day (and therefore onset and decay) of individual events and could be a particular issue with longer-lived events, like Queenstown wet and Fingal dry, where there may be more variability in event length and likely event start day. Given this potential issue, past studies have adjusted the start day of the individual events that make up their composite so that key dynamical features are aligned on the same day (e.g., Nakamura and Wallace 1993; Harrison and Larkin 1996; Laken and Čalogović 2013). For example, in their assessment of baroclinic eddy behavior in blocking onset, Nakamura and Wallace (1993) shifted the start date of selected events so that day 0 occurred when a target eddy became visible.
Additionally, they spatially shifted the center of their target eddy to coincide with a key grid point. This type of "preprocessing" of individual events may assist in reducing the noise in the composite. However, finding an automated, and indeed, defensible (Harrison and Larkin 1996), method for doing this is difficult. This is particularly so in our case, where we have driven our analysis by first defining the extreme rainfall events and then identifying any atmospheric processes associated with them, as opposed to knowing how the dynamics are set up from the outset, as was the case in Nakamura and Wallace (1993). As a result of this, we do not attempt event preprocessing in this study.

A further issue that could increase the noise in any composite analysis is ambiguous event definition. That is, our event definitions may actually be incorporating different types of extremes events and therefore 

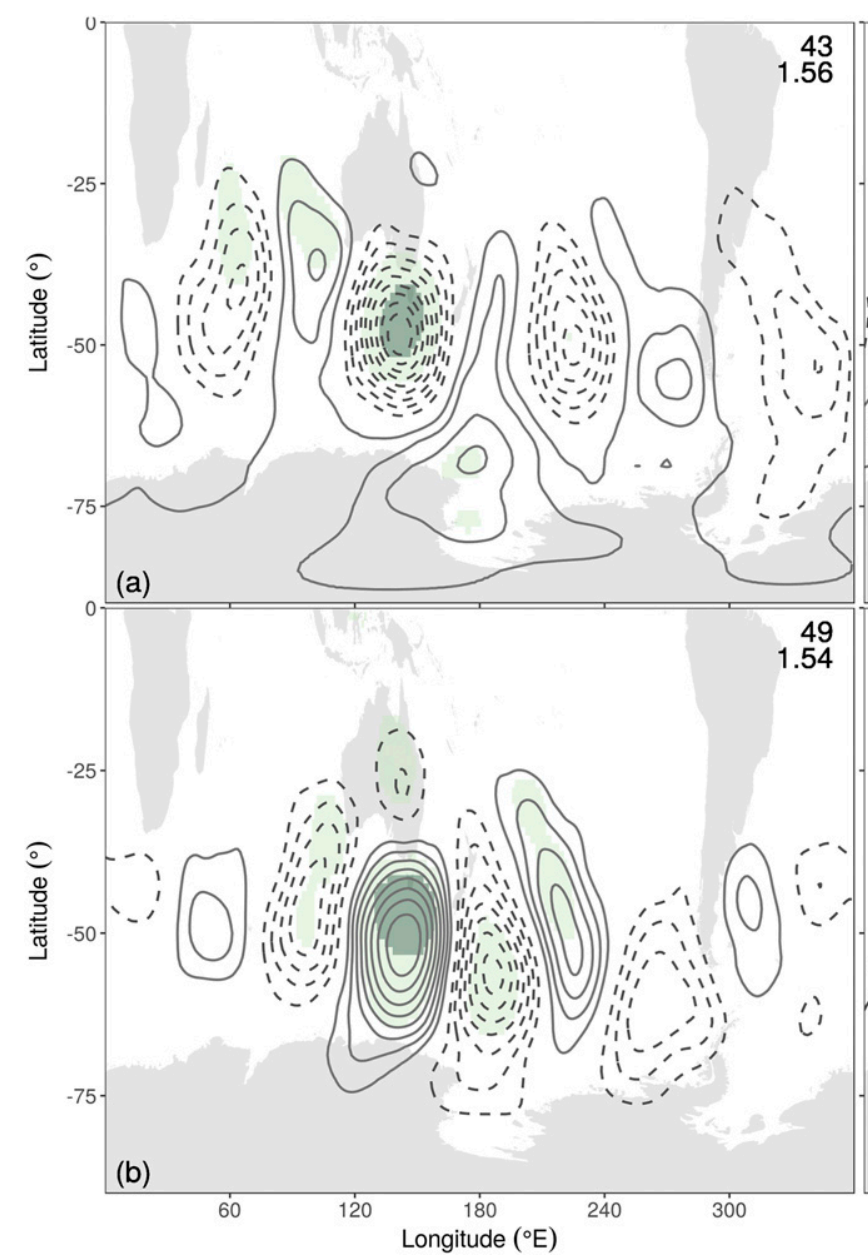
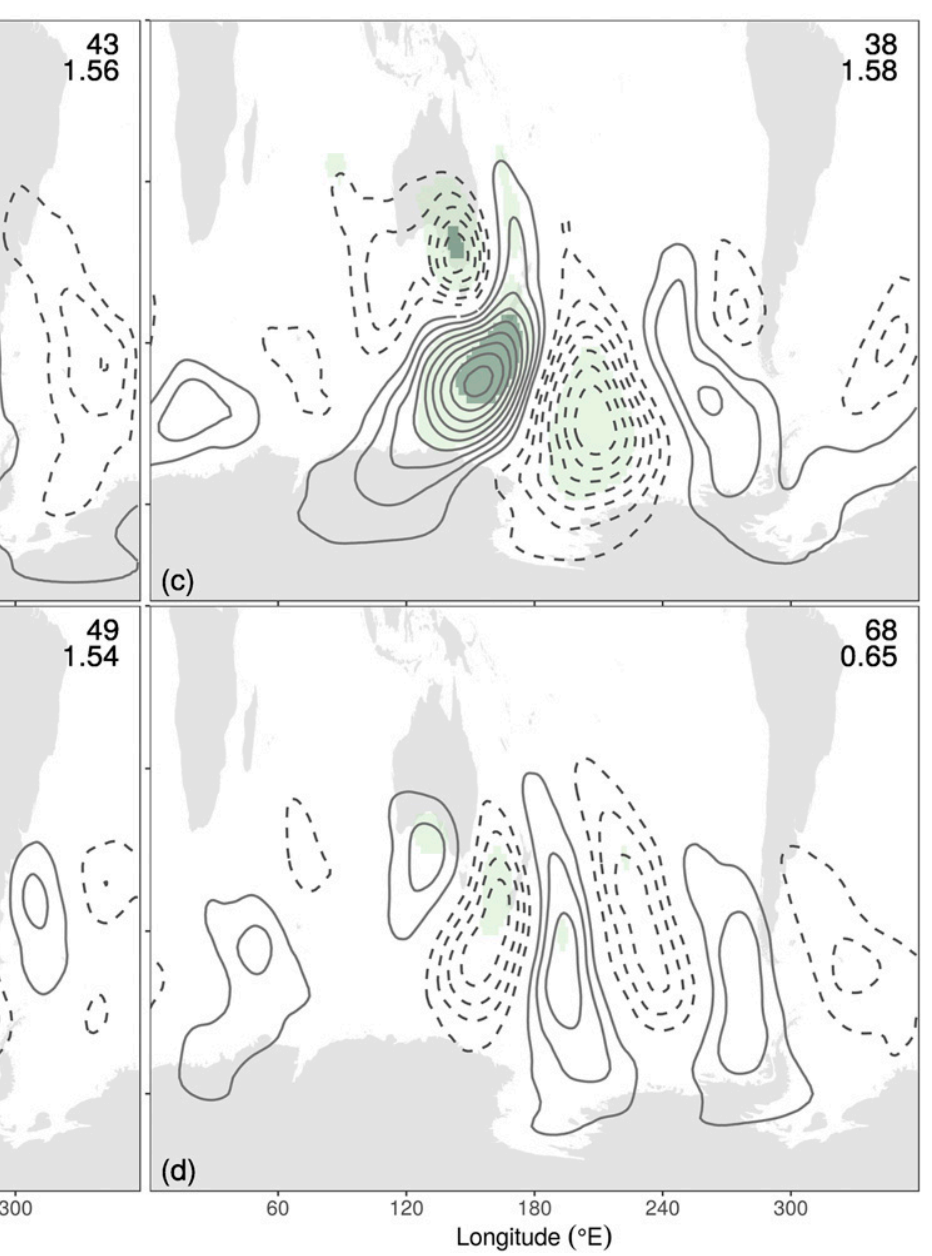

FIG. A2. Mean negative (dashed contours) and positive (solid contours) geopotential height anomalies for day 2 of (a) Queenstown wet, (b) Queenstown dry, (c) Fingal wet, and (d) Fingal dry events for autumn. The geopotential height anomalies presented here are the same as those presented in Figs. 4, 8, 12, and 15 for day 2. Green shading indicates the signal-to-noise ratio (ratio of absolute mean to standard deviation) of the geopotential height anomalies for day 2 of the events. Ratio values $>0.5$ are shaded light green, and values $>1$ are shaded dark green. The maximum ratio values are provided in the top-right corner for each event.

different dynamical signals into the one composite. One solution would be to refine the event definition, though this would undoubtedly decrease sample size, which would lead to the issues with sample size discussed above. In our wet extremes cases, we tested three different event definitions (as discussed in section 2) and identified similar composite patterns using all definitions for both Queenstown and Fingal. This provides some confidence that despite the noise in the composites (Figs. A2a,c), the dynamics associated with wet extreme events are consistent and robust to definition and that these dynamics are well represented by the composite patterns identified in Fig. 4 for Queenstown and Fig. 12 for Fingal. As discussed in section 3, the definition of dry events is difficult because unlike the wet end of the rainfall distribution, the dry end is bounded by zero and also heavily skewed toward zero, particularly in a generally dry location like Fingal (and indeed many locations across southern Australia). This means that there is little room to vary the dry event definition and also that only long sequences of dry days will form extreme events, which in turn means that dynamics at different time scales may be incorporated into the one composite. In this case, there would be a low signal-tonoise ratio and likely no coherent large-scale dynamical signature. Although there is some noise in the Fingal dry composite (Fig. A2d), we are able to identify a coherent wave train pattern in the composite and independently associate the PSA to dry extremes in Fingal (section 3d).

Where regions of low signal to noise are present in the composite patterns, one might reasonably interpret this as an indication that local synoptic features are dominant and that there is no association between 

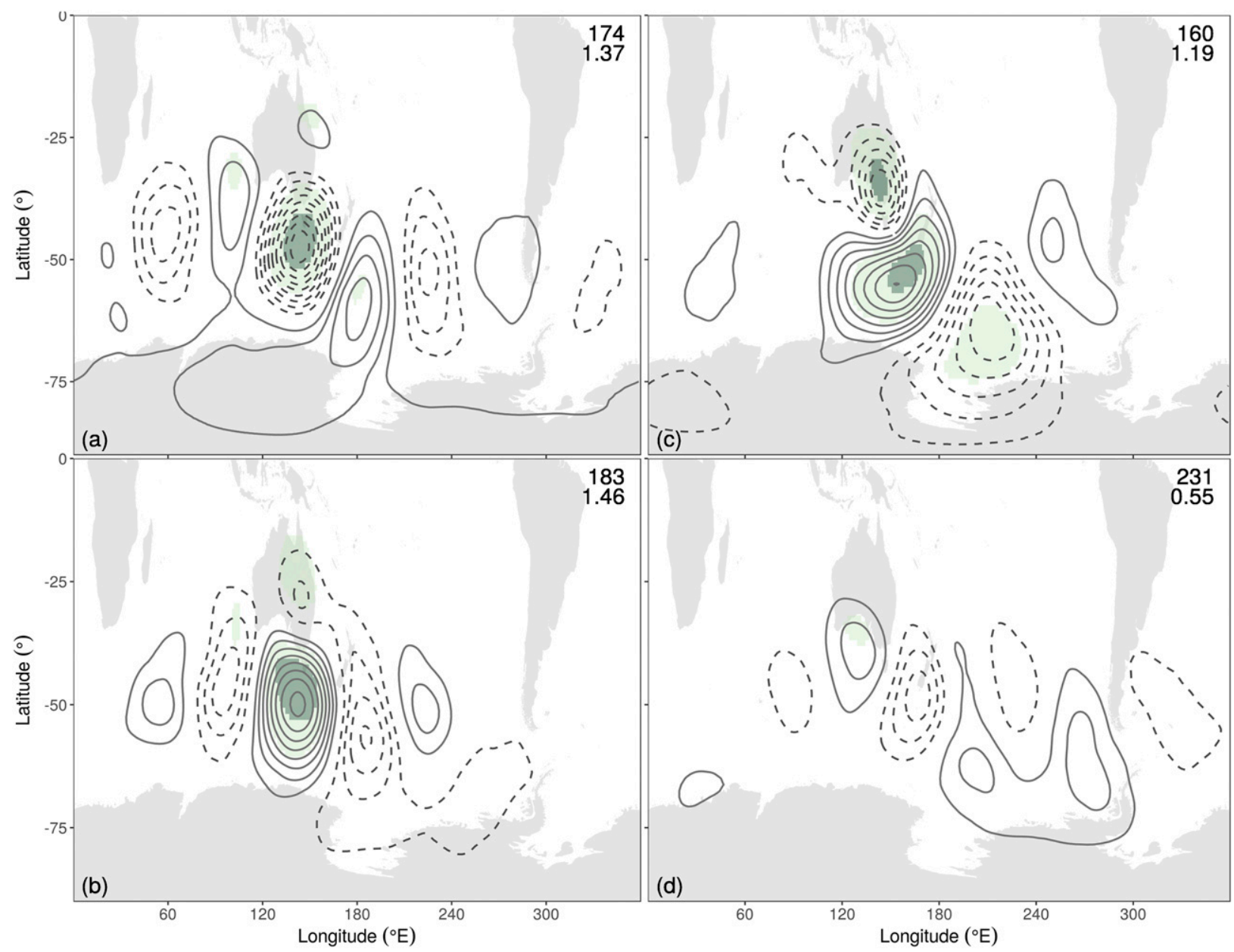

FIG. A3. As in Fig. A2, but for events identified across the full year.

large-scale wave train patterns and multiday rainfall extremes across Tasmania. However, the clear and coherent large-scale signals we identify for each composite for wet and dry extremes in Queenstown and Fingal, their significance relative to random samples (i.e., Monte Carlo analysis described above), and their association with the recurrent large-scale patterns of the PSA and IPA suggest that there is indeed a largescale atmospheric signal associated with extremes in Tasmania (section 3). Importantly, our results also align with existing literature on weather extremes and their association with large-scale wave trains across both hemispheres, as discussed in section 1 . That said, we do acknowledge the spread in the event samples in the analysis presented here, and without further assessment of individual extreme event variability (and potential event preprocessing described above), it is possible that not all multiday rainfall extremes in Queenstown and Fingal occur in association with a large-scale wave train pattern.

\section{REFERENCES}

Branstator, G., 2002: Circumglobal teleconnections, the jet stream waveguide, and the North Atlantic Oscillation. J. Climate, $\mathbf{1 5}$, 1893-1910, https://doi.org/10.1175/1520-0442(2002)015<1893: CTTJSW $>2.0 . \mathrm{CO} ; 2$.

Catto, J. L., and S. Pfahl, 2013: The importance of fronts for extreme precipitation. J. Geophys. Res. Atmos., 118, 1079110 801, https://doi.org/10.1002/jgrd.50852.

Ding, Q., and B. Wang, 2005: Circumglobal teleconnection in the Northern Hemisphere summer. J. Climate, 18, 3483-3505, https://doi.org/10.1175/JCLI3473.1.

Feldstein, S. B., and U. Dayan, 2008: Circumglobal teleconnections and wave packets associated with Israeli winter precipitation. Quart. J. Roy. Meteor. Soc., 134, 455-467, https://doi.org/ 10.1002/qj.225.

Frederiksen, J. S., 1982: A unified three-dimensional instability theory of the onset of blocking and cyclogenesis. J. Atmos. Sci., 39, 969-982, https://doi.org/10.1175/1520-0469(1982)039<0969: AUTDIT>2.0.CO;2.

_ 1983: A unified three-dimensional instability theory of the onset of blocking and cyclogenesis. II. Teleconnection patterns. J. Atmos. Sci., 40, 2593-2609, https://doi.org/10.1175/ 1520-0469(1983)040<2593:AUTDIT>2.0.CO;2. 
Goddard, L., and Coauthors, 2010: Providing seasonal-tointerannual climate information for risk management and decision-making. Procedia Environ. Sci., 1, 81-101, https://doi.org/ 10.1016/j.proenv.2010.09.007.

Godfred-Spenning, C., and T. Gibson, 1995: A synoptic climatology of rainfall in HEC catchments. Antarctic CRC Tech Rep. 5, 17 pp

Grazzini, F., 2007: Predictability of a large-scale flow conducive to extreme precipitation over the western Alps. Meteor. Atmos. Phys., 95, 123-138, https://doi.org/10.1007/s00703-006-0205-8.

- and F. Vitart, 2015: Atmospheric predictability and Rossby wave packets. Quart. J. Roy. Meteor. Soc., 141, 2793-2802, https://doi.org/10.1002/qj.2564.

Harrison, D. E., and N. K. Larkin, 1996: The COADS sea level pressure signal: A near-global El Niño composite and time series view, 1946-1993. J. Climate, 9, 3025-3055, https://doi.org/ 10.1175/1520-0442(1996)009<3025:TCSLPS $>2.0$.CO;2.

Hill, K. J., A. Santoso, and M. H. England, 2009: Interannual Tasmanian rainfall variability associated with large-scale climate modes. J. Climate, 22, 4383-4397, https://doi.org/10.1175/ 2009JCLI2769.1.

Hoskins, B. J., and P. J. Valdes, 1990: On the existence of stormtracks. J. Atmos. Sci., 47, 1854-1864, https://doi.org/10.1175/ 1520-0469(1990)047<1854:OTEOST>2.0.CO;2.

— , and T. Ambrizzi, 1993: Rossby wave propagation on a realistic longitudinally varying flow. J. Atmos. Sci., 50, 1661-1671, https:// doi.org/10.1175/1520-0469(1993)050<1661:RWPOAR >2.0.CO;2.

Irving, D., and I. Simmonds, 2016: A new method for identifying the Pacific-South American pattern and its influence on regional climate variability. J. Climate, 29, 6109-6125, https:// doi.org/10.1175/JCLI-D-15-0843.1.

Jeffrey, S. J., J. O. Carter, K. B. Moodie, and A. R. Beswick, 2001: Using spatial interpolation to construct a comprehensive archive of Australian climate data. Environ. Modell. Software, 16, 309-330, https://doi.org/10.1016/S1364-8152(01)00008-1.

Jones, D. A., W. Wang, and R. Fawcett, 2009: High-quality spatial climate data-sets for Australia. Aust. Meteor. Oceanogr. J., 58, 233-248, https://doi.org/10.22499/2.5804.003.

Kobayashi, S., and Coauthors, 2015: The JRA-55 reanalysis: General specifications and basic characteristics. J. Meteor. Soc. Japan, 93, 5-48, https://doi.org/10.2151/jmsj.2015-001.

Laken, B., and J. Calogović, 2013: Composite analysis with Monte Carlo methods: An example with cosmic rays and clouds. J. Space Wea. Space Climate, 3, A29, https://doi.org/10.1051/swsc/2013051.

Lau, K.-M., P.-J. Sheu, and I.-S. Kang, 1994: Multiscale low-frequency circulation modes in the global atmosphere. J. Atmos. Sci., 51, 1169-1193, https://doi.org/10.1175/1520-0469(1994)051<1169: MLFCMI $>2.0 . \mathrm{CO} ; 2$.

Lavery, B., G. Joung, and N. Nicholls, 1997: An extended highquality historical rainfall dataset for Australia. Aust. Meteor. Mag., 46, 27-38.

Lee, S., and I. M. Held, 1993: Baroclinic wave packets in models and observations. J. Atmos. Sci., 50,1413-1428, https://doi.org/ 10.1175/1520-0469(1993)050<1413:BWPIMA > 2.0.CO;2.

Lee, W.-J., and M. Mak, 1994: Observed variability in the large-scale static stability. J. Atmos. Sci., 51, 2137-2144, https://doi.org/ 10.1175/1520-0469(1994)051<2137:OVITLS > 2.0.CO;2.

Lewis, C. J., Y. Huang, S. T. Siems, and M. J. Manton, 2018: Wintertime orographic precipitation over western Tasmania J. South. Hemisphere Earth Syst. Sci., https://doi.org/10.22499/ 3.6801.003, in press.

Lucarini, V., D. Faranda, J. Milhazes Freitas, M. Holland, T. Kuna, M. Nicol, and S. Vaienti, 2016: Extremes and Recurrence in Dynamical Systems. Wiley, $312 \mathrm{pp}$.
Lynch, P., 1988: Deducing the wind from vorticity and divergence. Mon. Wea. Rev., 116, 86-93, https://doi.org/10.1175/1520-0493(1988) 116<0086:DTWFVA $>2.0 . \mathrm{CO} ; 2$

Mo, K. C., and R. W. Higgins, 1998: The Pacific-South American modes and tropical convection during the Southern Hemisphere winter. Mon. Wea. Rev., 126, 1581-1596, https://doi.org/ 10.1175/1520-0493(1998)126<1581:TPSAMA > 2.0.CO;2.

Müller, G. V., and T. Ambrizzi, 2007: Teleconnection patterns and Rossby wave propagation associated to generalized frosts over southern South America. Climate Dyn., 29, 633-645, https:// doi.org/10.1007/s00382-007-0253-x.

Nakamura, H., and J. M. Wallace, 1993: Synoptic behavior of baroclinic eddies during the blocking onset. Mon. Wea. Rev., 121, 1892-1903, https://doi.org/10.1175/1520-0493(1993)121<1892: SBOBED $>2.0 . \mathrm{CO} ; 2$

— M. Nakamura, and J. L. Anderson, 1997: The role of high- and low-frequency dynamics in blocking formation. Mon. Wea. Rev., 125, 2074-2093, https://doi.org/10.1175/1520-0493(1997) $125<2074$ :TROHAL $>2.0$. CO 2 .

O'Kane, T. J., and J. S. Frederiksen, 2008: A comparison of statistical dynamical and ensemble prediction methods during blocking. J. Atmos. Sci., 65, 426-447, https://doi.org/10.1175/ 2007JAS2300.1.

, J. S. Risbey, C. Franzke, I. Horenko, and D. P. Monselesan, 2013: Changes in the metastability of the midlatitude Southern Hemisphere circulation and the utility of nonstationary cluster analysis and split-flow blocking indices as diagnostic tools. J. Atmos. Sci., 70, 824-842, https://doi.org/10.1175/JAS-D-12-028.1.

,-- D. P. Monselesan, I. Horenko, and C. L. E. Franzke, 2016: On the dynamics of persistent states and their secular trends in the waveguides of the Southern Hemisphere troposphere. Climate Dyn., 46, 3567-3597, https://doi.org/10.1007/ s00382-015-2786-8.

— D. P. Monselesan, and J. S. Risbey, 2017: A multiscale reexamination of the Pacific-South American pattern. Mon. Wea. Rev., 145, 379-402, https://doi.org/10.1175/MWR-D-16-0291.1.

Pepler, A. S., and C. S. Rakich, 2010: Extreme inflow events and synoptic forcing in Sydney catchments. IOP Conf. Ser.: Earth Environ. Sci., 11, 012010, https://doi.org/10.1088/1755-1315/11/1/012010.

_ A. Coutts-Smith, and B. Timbal, 2014: The role of east coast lows on rainfall patterns and inter-annual variability across the east coast of Australia. Int. J. Climatol., 34, 1011-1021, https:// doi.org/10.1002/joc.3741.

Pezza, A. B., P. van Rensch, and W. Cai, 2012: Severe heat waves in southern Australia: Synoptic climatology and large scale connections. Climate Dyn., 38, 209-224, https://doi.org/10.1007/ s00382-011-1016-2.

Pfahl, S., 2014: Characterising the relationship between weather extremes in Europe and synoptic circulation features. Nat. Hazards Earth Syst. Sci., 14, 1461-1475, https://doi.org/10.5194/ nhess-14-1461-2014.

Pook, M. J., P. C. McIntosh, and G. A. Meyers, 2006: The synoptic decomposition of cool-season rainfall in the southeastern Australian cropping region. J. Appl. Meteor. Climatol., 45, 1156-1170, https://doi.org/10.1175/JAM2394.1.

- J. Risbey, and P. McIntosh, 2010: East coast lows, atmospheric blocking and rainfall: A Tasmanian perspective. IOP Conf. Ser.: Earth Environ. Sci., 11, 012011, https://doi.org/ 10.1088/1755-1315/11/1/012011.

Reeder, M. J., T. Spengler, and R. Musgrave, 2015: Rossby waves, extreme fronts, and wildfires in southeastern Australia. Geophys. Res. Lett., 42, 2015-2023, https://doi.org/10.1002/ 2015 GL063125. 
Risbey, J. S., M. J. Pook, P. C. McIntosh, M. C. Wheeler, and H. H. Hendon, 2009: On the remote drivers of rainfall variability in Australia. Mon. Wea. Rev., 137, 3233-3253, https://doi.org/ 10.1175/2009MWR2861.1.

_ P. C. McIntosh, and M. J. Pook, 2013a: Synoptic components of rainfall variability and trends in southeast Australia. Int. J. Climatol., 33, 2459-2472, https://doi.org/10.1002/joc.3597.

_ M. J. Pook, and P. C. McIntosh, 2013b: Spatial trends in synoptic rainfall in southern Australia. Geophys. Res. Lett., 40, 3781-3785, https://doi.org/10.1002/grl.50739.

_ - T. J. O'Kane, D. P. Monselesan, C. Franzke, and I. Horenko, 2015: Metastability of Northern Hemisphere teleconnection modes. J. Atmos. Sci., 72, 35-54, https://doi.org/10.1175/JASD-14-0020.1.

,,,--- C. L. E. Franzke, and I. Horenko, 2018: On the dynamics of austral heat waves. J. Geophys. Res. Atmos., 123, 38-57, https://doi.org/10.1002/2017JD027222.

Rogers, J. C., and H. van Loon, 1982: Spatial variability of sea level pressure and $500 \mathrm{mb}$ height anomalies over the Southern Hemisphere. Mon. Wea. Rev., 110, 1375-1392, https://doi.org/ 10.1175/1520-0493(1982)110<1375:SVOSLP>2.0.CO;2.

Sardeshmukh, P. D., and B. J. Hoskins, 1988: The generation of global rotational flow by steady idealized tropical divergence. J. Atmos. Sci., 45, 1228-1251, https://doi.org/10.1175/15200469(1988)045<1228:TGOGRF>2.0.CO;2.
Shimizu, M. H., and I. F. de Albuquerque Cavalcanti, 2011: Variability patterns of Rossby wave source. Climate Dyn., 37, 441454, https://doi.org/10.1007/s00382-010-0841-z.

Takaya, K., and H. Nakamura, 1997: A formulation of a waveactivity flux for stationary Rossby waves on a zonally varying basic flow. Geophys. Res. Lett., 24, 2985-2988, https://doi.org/ 10.1029/97GL03094.

_ and - 2001: A formulation of a phase-independent waveactivity flux for stationary and migratory quasigeostrophic eddies on a zonally varying basic flow. J. Atmos. Sci., 58, 608-627, https:// doi.org/10.1175/1520-0469(2001)058<0608:AFOAPI >2.0.CO;2.

Teng, H., and G. Branstator, 2017: Causes of extreme ridges that induce California droughts. J. Climate, 30, 1477-1492, https:// doi.org/10.1175/JCLI-D-16-0524.1.

Thompson, D. W. J., and J. M. Wallace, 2000: Annular modes in the extratropical circulation. Part I: Month-to-month variability. J. Climate, 13, 1000-1016, https://doi.org/10.1175/1520-0442(2000) 013<1000:AMITEC>2.0.CO;2.

Trenberth, K. F., and K. C. Mo, 1985: Blocking in the Southern Hemisphere. Mon. Wea. Rev., 113, 3-21, https://doi.org/10.1175/ 1520-0493(1985)113<0003:BITSH > 2.0.CO;2.

Wirth, V., M. Riemer, E. K. M. Chang, and O. Martius, 2018: Rossby wave packets on the midlatitude waveguide-A review. Mon. Wea. Rev., 146, 1965-2001, https://doi.org/10.1175/ MWR-D-16-0483.1. 